\title{
Event-Related Potentials Differentiate the Effects of Aging on Word and Nonword Repetition in Explicit and Implicit Memory Tasks
}

\author{
Diane Swick and Robert T. Knight \\ University of California, Davis, and Veterans Affairs Outpatient Clinic, Martinez
}

\begin{abstract}
Explicit memory declines with age while implicit memory remains largely intact. These experiments extended behavioral findings by recording event-related potentials (ERPs) in young and elderly adults during repetition priming and recognition memory paradigms. Words and pronounceable nonwords repeated after 1 of 3 delays. Stimuli were categorized as either word-nonword or old-new. Repeated items elicited more positive-going potentials in both tasks. Hemispheric asymmetries for word and nonword processing were observed during lexical decision: Repetition effects were larger over the left hemisphere for words and over the right hemisphere for nonwords. For the young, ERP repetition effects were larger during recognition memory. For old adults, conversely, repetition produced more positive-going waveforms during lexical decision. The elderly had ERP and behavioral deficits at long recognition delays. ERP repetition effects in the elderly, like behavioral performance, were preserved in an implicit task but impaired in an explicit memory task.
\end{abstract}

Neuropsychological studies of amnesic patients have facilitated the classification of memory into different subsystems (see Polster, Nadel, \& Schacter, 1991; Squire, Knowlton, \& Musen, 1993; Tulving, 1983, for reviews). Explicit memory is exemplified by an ability to overtly recall some event or recognize a particular stimulus presented in the past, whereas implicit memory does not require deliberate recollection but involves a change in test performance resulting from prior exposure to specific information (Schacter, Chiu, \& Ochsner, 1993; Tulving \& Schacter, 1990). Although patients with severe anterograde amnesia are unable to recall or recognize material presented only a few minutes ago (Milner, 1965), they may show behavioral evidence that the same information influences performance on a variety of tasks tapping implicit memory (Cermak, Chandler, \& Wolbarst, 1985; Gordon, 1988; Graf, Squire, \& Mandler, 1984; Moscovitch, 1982a; Tulving, Hayman, \& Macdonald, 1991; Warrington \& Weiskrantz, 1970).

Although not an inevitable consequence of aging, memory loss is a common complaint in the elderly. A number of studies have shown that explicit memory, particularly measures of episodic memory such as recall and recognition, declines with age while implicit memory remains relatively

Diane Swick and Robert T. Knight, Center for Neuroscience, University of California, Davis, and Department of Neurology, Veterans Affairs Outpatient Clinic, Martinez.

This research was supported by Javits Award NS21135 from the National Institute of Neurological Disorders and Stroke (NINDS), NS17778 from the NINDS, and the McDonnell-Pew Center for Cognitive Neuroscience, University of California, Davis.

We thank Claude Alain, Linda Chao, Lynn Nielsen-Bohlman, Keith Ogawa, and Donatella Scabini for helpful comments on an earlier version of this article.

Correspondence concerning this article should be addressed to Diane Swick, Department of Neurology, Veterans Affairs Outpatient Clinic, 150 Muir Road, Martinez, California 94553. Electronic mail may be sent via Internet to diane@marva4.ncsc.med.va.gov. intact, a finding qualitatively similar to that observed in amnesia (reviewed in Light, 1991; Mitchell, 1989; Shimamura, 1990). For example, older adults showed priming of comparable magnitude to young adults in word stem completion (Java \& Gardiner, 1991; Light \& Singh, 1987; see also Chiarello \& Hoyer, 1988; Davis et al., 1990, for conflicting results), word fragment completion (Light, Singh, \& Capps, 1986), perceptual identification of briefly presented or degraded stimuli (Light \& Singh, 1987), lexical decision (Moscovitch, 1982b), and picture naming (Mitchell, 1989). Free recall, cued recall, and recognition memory performance of these older adults, however, was impaired relative to the young participants.

Two major theories for interpreting word repetition effects are the abstractionist and episodic accounts. The logogen model of Morton (1969) typifies abstractionist, or lexical, explanations. Presentation of a word transiently activates its abstract lexical representation (logogen), thereby lowering the logogen's threshold for subsequent activation. One problem with this viewpoint is that repetition effects are reduced with a change in modality (Clarke \& Morton, 1983; Jacoby \& Dallas, 1981), suggesting that "nonmodal" lexical units do not entirely account for priming effects. Another difficulty is that priming can occur for novel material such as nonwords, which have no preexisting representations in the lexicon (Feustel, Shiffrin, \& Salasoo, 1983). Finally, priming is observed for nonverbal stimuli such as unfamiliar objects (Schacter, Cooper, \& Delaney, 1990) and line patterns (Musen \& Treisman, 1990), indicating that nonlexical mechanisms can mediate repetition effects.

Episodic theories, conversely, postulate that the initial presentation of a stimulus establishes an episodic memory trace that is accessed when the item is repeated (Forster \& Davis, 1984; Jacoby \& Dallas, 1981). This view holds that priming effects are too long lasting to be accommodated by the temporary activation of a logogen. Jacoby and Dallas argued (along with Mandler, 1980) that recognition memory 
consists of two types of decisions: (a) judgments of relative perceptual fluency and (b) elaboration of an item's original context, with the former responsible for repetition effects. Forster and Davis maintained that "the repetition effect is a composite effect," with a short-term component mediated by lexical factors and a long-term component mediated by episodic influences. One objection to the episodic model, however, is that amnesic patients demonstrate dissociations between explicit and implicit versions of the same task (Graf et al., 1984). Young adults can also show priming that is independent of conscious recollection (Jacoby \& Dallas, 1981; Tulving, Schacter, \& Stark, 1982).

An alternative position to the abstractionist versus episodic dilemma is to postulate a number of priming mechanisms specific to each type of repetition effect, as in Tulving and Schacter's (1990) hyperspecific and distinct perceptual representation systems (PRS) for visual word forms and visual objects. They view conceptual priming (e.g., word association, category exemplar production) as a product of semantic memory, which is distinct from both PRS and episodic memory.

Certain characteristics of nonword priming present challenges not only for abstractionist models but also for episodic and PRS accounts. In the case of episodic models, the semantic representations of words can facilitate the formation of episodic memory traces, which would lead to stronger priming for words. Depending on the task and conditions, however, nonword repetition effects may not be obtained at all, even when nonword episodic traces were presumably formed. A greater problem arises if nonword priming is based on resemblance to visual word forms because repetition effects for orthographically legal nonwords should closely resemble those for words. Some researchers have demonstrated nonword priming in lexical decision (Kersteen-Tucker, 1991; Scarborough, Cortese, \& Scarborough, 1977), whereas others have not (Bowers, 1994; Forbach, Stanners, \& Hochhaus, 1974; Forster \& Davis, 1984). Typically, the effects in lexical decision have been very short lived (Bentin \& Moscovitch, 1988; KersteenTucker, 1991), although longer duration effects have been found (Gordon, 1988; Scarborough et al., 1977, Experiment 2; Smith \& Oscar-Berman, 1990). Nonword priming in perceptual identification, including long-term effects, has been seen more consistently (Cermak et al., 1985; Feustel et al., 1983; Haist, Musen, \& Squire, 1991; Reuckl, 1990).

The alternative hypotheses for explaining priming effects have different predictions about what types of changes might be observed with aging. If semantic memory is preserved in aging (Light, 1991; Mitchell, 1989), abstractionist models predict intact priming in the elderly. Episodic accounts, by their nature, predict some degree of impairment in indirect memory tasks. Conversely, memory taxonomies based on episodic-semantic-PRS (Tulving \& Schacter, 1990) and declarative-nondeclarative (Squire, 1992) distinctions predict comparable implicit memory in young and older adults; priming decrements in the elderly, if they occur at all, would be independent of changes in semantic and episodic memory.

Event-related brain potentials (ERPs) can elucidate the timing of the neural events underlying aspects of memory such as encoding and retrieval, augmenting standard behavioral performance measures (Hillyard \& Picton, 1987; Swick, Kutas, \& Neville, 1994). Application of the ERP methodology can potentially illuminate controversies surrounding the nature, location, and duration of repetition effects in young and older adults. Another advantage of ERPs is that hemispheric asymmetries in stimulus processing can be assessed covertly. ${ }^{1}$ Additionally, recordings from an array of electrode sites can reveal scalp distribution (and presumably, functional) differences between young and older adults or between words and nonwords.

One widely investigated ERP component is the P300, a positive potential that occurs $300-600 \mathrm{~ms}$ following detection of infrequent target stimuli (the "oddball" paradigm; e.g., Squires, Squires, \& Hillyard, 1975). Related latepositive components (LPCs) have been recorded in other paradigms, including the repetition of words in lists, sentences, and text (Besson, Kutas, \& Van Petten, 1992; Rugg \& Nagy, 1989; Van Petten, Kutas, Kluender, Mitchiner, \& McIsaac, 1991). LPCs recorded in these tasks may contain overlapping contributions from $\mathrm{P} 300$ and other potentials related to repetition and retrieval from secondary memory (Smith \& Guster, 1993). Another component extensively studied in language processing tasks is the $\mathrm{N} 400$, a negative potential modulated by the extent to which a word is related to its prior context (see Kutas \& Van Petten, 1988, 1994, for reviews). In semantic priming studies, $\mathrm{N} 400$ amplitude was larger for targets preceded by unrelated primes than by related primes (Bentin, McCarthy, \& Wood, 1985).

The effect of word repetition on ERPs is a wellcharacterized phenomenon. Repeated words elicit greater positivity than new words in a variety of paradigms, including lexical decision, semantic categorization, and continuous recognition memory (Bentin, Moscovitch, \& Heth, 1992; Friedman, 1990; Halgren \& Smith, 1987; Karayanidis, Andrews, Ward, \& McConaghy, 1991; Rugg \& Nagy, 1989). Word repetition decreases $\mathrm{N} 400$ and enhances LPC amplitude, both when a categorical response is required and when one is not. An open question is how closely related this positive-going, ERP repetition effect is to implicit versus explicit aspects of memory retrieval. Its relationship to explicit retrieval was bolstered by the finding that remembered items associated with "conscious recollection" evoked larger positive shifts than items associated with only "general familiarity" (Smith, 1993). Likewise, words studied in a semantic task elicited greater positivity on subsequent presentation than words studied in a nonsemantic task (Paller, Kutas, \& McIsaac, 1995). Presumably, this level-ofprocessing manipulation affects explicit memory (better recall and recognition following the semantic study task) but not implicit memory. Participants were more likely to

\footnotetext{
${ }^{1}$ Caution must be used in interpreting ERP scalp topography, including hemispheric effects, because the location of the underlying neural generators occasionally can be paradoxical (see Kounios \& Holcomb, 1994, for discussion). We agree with these authors, however, that scalp distribution and hemispheric differences between conditions are reflections of functional differences.
} 
engage in conscious recollection for words studied in the deeper task.

Others have argued that the ERP repetition effect is more closely associated with relative familiarity and implicit memory (Friedman, Hamberger, Stern, \& Marder, 1992; Rugg \& Doyle, 1992; Rugg, Pearl, Walker, Roberts, \& Holdstock, 1994). Rugg and Doyle initially used word frequency effects to support the relative familiarity interpretation. Later writings (Rugg, 1995), however, acknowledged that the recognition advantage (and larger ERP repetition effects) for low frequency words could be due to better recollection instead of greater perceptual fluency. Another avenue of support for familiarity or implicit memory involvement was provided by Alzheimer's patients, who despite their well-documented deficits in explicit memory demonstrated significant ERP effects when word repetition was incidental to the task (Friedman et al., 1992; Rugg et al., 1994).

Like the behavioral priming model of Forster and Davis (1984), a third alternative is that the ERP repetition effect is a composite effect, with contributions from neural sources participating in both explicit and implicit aspects of word repetition (Swick \& Knight, 1995). Previous studies have proposed this model as well. In a perceptual identification task, a positive component from 400 to $500 \mathrm{~ms}$ may have reflected processes related to priming, whereas a later positivity (500-800 ms) indexed recollection (Paller \& Kutas, 1992). Bentin et al. (1992) speculated that LPC amplitude was sensitive to the strength of the memory trace in both explicit and implicit paradigms. LPC amplitude was sensitive to word repetition in a recognition task, regardless of whether the participants remembered seeing the word. ${ }^{2}$ In lexical decision, LPC amplitude was sensitive to the recency and number of repetitions, although reaction time (RT) priming was not.

Recent studies have examined the effects of aging on ERPs elicited in implicit word repetition tasks. In both covert and overt lexical decision paradigms, the onset of LPC evoked by repeated words did not differ among young, middle-aged, and older participants, although its duration was prolonged in the elderly (Karayanidis et al., 1993). No age differences in mean RT or percentage of priming were observed in the overt condition. Likewise, in semantic classification tasks, LPC amplitude and RT priming were not affected by aging, although LPC latency was delayed in middle-aged and elderly adults (Friedman et al., 1992; Hamberger \& Friedman, 1992). Thus, both behavioral and ERP measures of repetition priming suggest that these processes are intact in the elderly.

Conversely, aging altered ERPs and behavioral performance during a visual recognition memory task (NielsenBohlman \& Knight, 1995). Line drawings of familiar objects were repeated either immediately or after longer delays. Immediate repetitions elicited enhanced LPCs and comparable accuracy in both young and older participants. However, delayed repetitions resulted in reduced LPC amplitudes and decreased accuracy in the elderly, particularly for the longer delays. These data suggested that immediate memory is intact in the elderly, with electrophysiological and behavioral deficits apparent only at longer delays.

The present experiments were designed to test the hypothesis that the effects of aging can dissociate electrophysiological signs of stimulus repetition in implicit and explicit memory tasks, similar to extensive findings in the behavioral literature. We manipulated lag to determine the effects of aging on the ERP repetition effect at different temporal delays. Behavioral (Bentin \& Moscovitch, 1988; Forster \& Davis, 1984) and ERP ${ }^{3}$ (Bentin \& Peled, 1990; NielsenBohlman \& Knight, 1995) evidence indicates that repetition effects can be divided into short-term and long-term components. We also addressed the questions of whether the ERPs elicited by pronounceable nonwords differ from those elicited by words and whether the effects of word and nonword repetition are the same. These experiments allowed comparisons between ERPs elicited by preexisting, linguistic entities versus items that have no prior existence in the lexicon or in semantic memory (as entire units; see Dorfman, 1994).

\section{General Method}

\section{Participants}

Participants were 9 young people recruited from nearby colleges (mean age $=23.0$ years, range $=18-32$ ) and 9 healthy, older individuals recruited from the surrounding communities $(M=67.6$ years, range $=57-83$ ). Participants with a history of psychiatric or neurological problems or psychoactive drug use were excluded. The two groups were matched for education level: 14.6 years for young and 13.4 years for elderly. All participants were right handed except for 1 elderly person (left handed) and 1 young person (slightly ambidextrous). English was the primary language for all participants. Two young people and 1 elderly person were bilingual, 1 young and 1 elderly were moderately fluent in a second language, 2 young were taking classes in a second language, whereas 1 elderly had some familiarity with a second language. Participants were paid for their participation and signed informed consent statements approved by the Institutional Review Board of the Martinez Veterans Affairs Outpatient Clinic and the University of California, Davis.

\section{Stimuli and Tasks}

Stimuli were words and pronounceable nonwords, four to eight letters in length. Words were of moderate-to-low frequency, less than 30 occurrences/million according to the Francis and Kučera (1982) count, with a mean of $9.35 /$ million. Half of the words were concrete, the other half were abstract. Nonwords were created by altering one-three letters in real words or rearranging their sequence. Two lists of 180 words and 180 pronounceable nonwords were constructed ( 360 total stimuli in each list). Approximately 90 items occurred in each block: 22-23 words (half concrete and half

\footnotetext{
${ }^{2}$ Other investigators, however, have not observed this effect when young participants failed to recognize old words (see our Results section: Experiment 2, hits versus misses; Neville, Kutas, Chesney, \& Schmidt, 1986; Rugg, 1995).

${ }^{3}$ These differences were in recognition memory paradigms. Some groups have not found differences between immediate and delayed repetition for lexical decision (Nagy \& Rugg, 1989; Bentin \& Peled, 1990), whereas others have (Karayanidis et al., 1991).
} 
abstract) and 22-23 nonwords, with all stimuli repeating once within the block. A total of eight blocks was presented in one session, with the order counterbalanced across subjects. Rest periods were given after each block. Lags (delays) between first and second presentation were $3 \mathrm{~s}$ (from onset of first stimulus to onset of repeated stimulus, 0 intervening items), 6-12 s (1-3 intervening items), and 30-60 s (9-19 intervening items). Stimulus duration was $500 \mathrm{~ms}$, whereas the interstimulus interval was 2,500 ms. Two separate practice lists were constructed, each consisting of 24 stimuli in the proportions described above.

For 5 young and all elderly participants, two different response conditions were presented in separate sessions: (a) lexical decision, in which participants discriminated between words and nonwords; and (b) continuous recognition, in which participants discriminated between new and old items (both words and nonwords). Stimulus lists and the order of tasks were counterbalanced across subjects. Four young participants chose to complete both experiments in one session. A 15-20-min rest break was given between tasks, with the order again counterbalanced.

\section{ERP Recording}

Electrophysiological signals were recorded by using an ElectroCap, with electrode placements according to the 10-20 International System (Jasper, 1958), at Fp1, Fp2, Fz, F3, F4, F7, F8, Cz, C3, C4, Pz, P3, P4, T3, T4, T5, T6, O1, and O2 referred to linked mastoids. Eye movements were monitored by electrodes placed below and lateral to the left eye, also referred to linked mastoids. Signals were amplified $(\times 50,000)$ and filtered $(0.1-100 \mathrm{~Hz})$ via a Grass Neurodata acquisition system. The electroencephalogram was continuously digitized at $250 \mathrm{~Hz}$ per channel and stored on magnetic tape for subsequent analysis. The reconding epoch was $1,024 \mathrm{~ms}$.

\section{Data Analysis}

ERP averages for each stimulus type (word and nonword) and condition (new, lag 0, lag 1-3, and lag 9-19) were computed for individual participants, grand averages were computed separately across subjects for young and elderly. Trials contaminated by eye movements, excessive peak-to-peak deflection (over $100 \mu \mathrm{V}$ ), and amplifier blocking were automatically rejected from the averaged data. Difference waveforms were derived by subtracting ERPs to new stimuli from ERPs to repeated stimuli or ERPs to nonwords from ERPs to words. ERPs were quantified by computing mean amplitudes in defined latency windows in relation to a $100-\mathrm{ms}$ prestimulus baseline. For both lexical decision and recognition memory tasks, ERPs were sorted into first and second presentations (three delays) of words and nonwords. Additionally, response accuracy and RT data were compared across the young and the elderly.

Statistical analyses were carried out on IBM and Macintosh computer systems by using repeated-measures analyses of variance (ANOVAs). Geisser-Greenhouse corrections for multiple comparisons were used when appropriate; the corrected $p$ values and the uncorrected degrees of freedom are reported. ERP mean amplitude measures were analyzed by stimulus type, repetition condition, age group, task, and electrode. The main effect of electrode is uninteresting (and therefore not recounted), but differences in scalp distribution across conditions and between groups were also analyzed after normalization of the data (McCarthy \& Wood, 1985). This procedure allows for the possibility that a given scalp distribution effect could be due to multiplicitive differences in neural source strength across conditions. Hence, any interaction involving the electrode factor was reported only if significant in the normalized data set. Behavioral response accuracy and RTs were analyzed by stimulus type, repetition, and group.

\section{Experiment 1}

This experiment was designed to assess preferentially indirect, or implicit, memory systems. In the present version of the lexical decision task, both stimulus types repeated after one of three lags. This repetition was incidental to the task, although explicit strategies could influence behavioral and ERP responses. Previous word repetition studies have found that RT and ERP measures of priming are unimpaired in older adults in indirect paradigms (Hamberger \& Friedman, 1992; Light, 1991). Here our aim was to replicate and extend this finding to nonword repetition in the elderly. If nonword priming is more dependent on episodic factors and less influenced by lexical and semantic memory than word priming, the elderly may demonstrate deficits due to an age-related decline in episodic memory. Participants were seated in a dim, sound-attenuated booth. An asterisk was presented at the center of the screen to signal the start of each block. Then a series of words and nonwords was presented. Participants pressed one button for words and the other button for nonwords, using the thumbs of both hands. They were told that although some items might repeat, this was not important, and they were instructed to respond as quickly and as accurately as possible. The hands used for word and nonword responses were counterbalanced across subjects. After two short practice blocks, the first of eight experimental blocks was presented.

\section{Results}

\section{Performance}

RT data were subjected to a three-way ANOVA with factors of age (young vs. old), stimulus type (word vs. nonword), and repetition (new, lag 0, lag 1-3, and lag 9-19). Significant main effects of stimulus type, $F(1,16)=33.36$, $p<.0001$, and repetition, $F(3,48)=126.71, p<.0001$, were obtained. Participants were faster for words than for nonwords and for repeated items at all lags compared with new stimuli (see Table 1). An interaction between stimulus type and repetition was also observed, $F(3,48)=4.91, p<$ .05 , with greater differences for words than for nonwords. Separate ANOVAs revealed significant repetition effects for both stimulus types: words, $F(3,48)=152.69$, and nonwords, $F(3,48)=52.17$ (both $p s<.0001$ ). There were no main or interactive effects of age, the latter result suggesting that the elderly showed priming of equivalent magnitude to young adults.

Additional analyses assessed priming separately for each stimulus type with planned comparisons between new items and repeated items at each lag. Repetition priming was significant at all delays for words $(p s<.0001)$ and for nonwords at the two shorter delays $(p s<.0001)$. Nonword priming at lag 9-19 showed a trend toward significance $(p<.08)$. Although the three-way interaction between repetition, stimulus type, and age was not significant, planned comparisons analyzed priming separately for each age group 
Table 1

Mean Reaction Times (RTs, in Milliseconds) and Priming (in Percentages) for the Lexical Decision Task

\begin{tabular}{|c|c|c|c|c|c|c|c|c|}
\hline \multirow[b]{3}{*}{ Condition } & \multicolumn{4}{|c|}{ Words } & \multicolumn{4}{|c|}{ Nonwords } \\
\hline & \multicolumn{2}{|c|}{ Young } & \multicolumn{2}{|c|}{ Elderly } & \multicolumn{2}{|c|}{ Young } & \multicolumn{2}{|c|}{ Elderly } \\
\hline & $\boldsymbol{M}$ & $S E M$ & $M$ & $S E M$ & $M$ & $S E M$ & $M$ & SEM \\
\hline \multicolumn{9}{|l|}{ RT } \\
\hline $\begin{array}{l}\text { New } \\
\text { Lag 0 } \\
\operatorname{Lag} 1-3 \\
\operatorname{Lag} 9-19\end{array}$ & $\begin{array}{l}764.6 \\
593.2 \\
667.8 \\
688.6\end{array}$ & $\begin{array}{l}48.4 \\
50.8 \\
43.1 \\
45.0\end{array}$ & $\begin{array}{l}785.7 \\
583.6 \\
687.7 \\
690.0\end{array}$ & $\begin{array}{l}52.8 \\
41.5 \\
51.1 \\
45.8\end{array}$ & $\begin{array}{l}868.9 \\
679.6 \\
770.5 \\
826.0\end{array}$ & $\begin{array}{l}59.8 \\
72.7 \\
50.9 \\
68.2\end{array}$ & $\begin{array}{l}822.9 \\
644.4 \\
769.8 \\
806.5\end{array}$ & $\begin{array}{l}40.2 \\
36.2 \\
39.1 \\
54.0\end{array}$ \\
\hline Priming (\%) & & & & & & & & \\
\hline Lag 0 & 23.1 & 1.9 & 25.7 & 1.2 & 23.0 & 3.0 & 21.8 & 1.5 \\
\hline Lag 1-3 & 12.7 & 1.1 & 12.7 & 1.0 & 11.2 & 1.3 & 6.8 & 1,9 \\
\hline Lag 9-19 & 10.0 & 0.9 & 12.1 & 0.7 & 5.4 & 2.0 & 2.4 & 2.7 \\
\hline
\end{tabular}

and each stimulus type, ${ }^{4}$ revealing that nonword priming at lag 9-19 was significant in the young but not in the elderly. For young participants, repetition priming was significant at all delays for words $(\operatorname{lag} 0, p<.0001$; $\operatorname{lag} 1-3, p<.001$; lag $9-19, p<.005$ ) and for nonwords (lag $0, p<.0001$; lag $1-3, p<.001$; lag $9-19, p<.05$ ). For older participants, word repetition was significant at all delays ( $p s<.001$ ), whereas nonword repetition was significant at lag 0 $(p<.001)$ and lag $1-3(p<.05)$, but not at lag $9-19$ $(p>.27)$.

In Table 1, priming is shown as a percentage of RT facilitation for the three delays, each compared with first presentation. Priming was greater for immediately repeated stimuli than for delayed repetitions and for words compared with nonwords, with the older group responsible for this latter result. Significant main effects of stimulus type, $F(1$, $16)=14.54, p<.005$, and lag, $F(2,32)=87.17, p<.0001$, were observed, with a marginal Stimulus Type $\times$ Age interaction, $F(1,16)=3.91, p<.07$. The elderly showed significantly less priming for nonwords than for words, $F(1$, $8)=20.19, p<.005$, whereas the young did not, $F(1,8)=$ 1.49. A Stimulus Type $\times$ Repetition interaction was also seen, $F(2,32)=3.83, p<.05$. Paired $t$ tests demonstrated that word priming was greater than nonword priming for lag $1-3$ and lag 9-19 ( $p$ s $<.005$ ), but not for lag 0 ( $p>.21$ ).

Accuracy data (percentage of errors in each condition) were analyzed by a three-way ANOVA with variables of age, stimulus type, and repetition. Overall, participants made few errors in this task; the percentage of errors was greater for new than for repeated items, particularly for words (see Table 2). The effect of repetition, $F(3,48)=9.92, p<.001$, and the Stimulus Type $\times$ Repetition interaction, $F(3,48)=$ $4.57, p<.05$, were significant. No main or interactive effects of age were found for accuracy.

\section{ERPs}

Words. In young participants, new words elicited a small N400 followed by a LPC, which peaked at 550-650 ms (Figure 1). Repeated words began to diverge from new words at $200 \mathrm{~ms}$ with a more positive-going waveform, particularly at central and posterior electrodes. Word repetition yielded much smaller effects at frontal electrodes. Immediate repeats elicited the largest and earliest positivity, but repetition effects were also observed at the two longer lags. In older adults, the $\mathrm{N} 400$ elicited by new words was delayed and difficult to discern in most participants (Figure 1). Similar to young adults, immediate repeats elicited the greatest positivity, and LPC was also enhanced at longer delays. Although LPC latency was delayed by $50-100 \mathrm{~ms}$ in older participants, the repetition effect was of longer duration, lasting until $700 \mathrm{~ms}$ for the two longer delays. Across all conditions, the elderly showed enhanced positivity at frontal sites compared with the young.

Nonwords. The presentation of new and repeated nonwords elicited ERPs that were qualitatively similar to those elicited by words, particularly in the elderly (Figure 2). In the young, nonwords evoked a more negative-going waveform at frontal and central electrodes from 300 to $500 \mathrm{~ms}$. This difference between words and nonwords was smaller in the elderly. The LPC evoked by nonwords was decreased in amplitude and delayed in latency, although the effects of

Table 2

Error Rates (in Percentages) for the Lexical Decision Task

\begin{tabular}{|c|c|c|c|c|c|c|c|c|}
\hline \multirow[b]{3}{*}{ Condition } & \multicolumn{4}{|c|}{ Words } & \multicolumn{4}{|c|}{ Nonwords } \\
\hline & \multicolumn{2}{|c|}{ Young } & \multicolumn{2}{|c|}{ Elderly } & \multicolumn{2}{|c|}{ Young } & \multicolumn{2}{|c|}{ Elderly } \\
\hline & $M$ & $S E M$ & $M$ & $S E M$ & $M$ & $S E M$ & $M$ & $S E M$ \\
\hline New & 4.51 & 0.71 & 7.35 & 2.18 & 6.15 & 2.51 & 3.77 & 0.97 \\
\hline $\operatorname{Lag} 0$ & 2.43 & 0.69 & 2.22 & 0.62 & 3.76 & 2.16 & 1.11 & 0.62 \\
\hline Lag 1-3 & 2.42 & 0.69 & 2.69 & 1.11 & 5.93 & 2.70 & 3.71 & 1.80 \\
\hline Lag 9-19 & 1.79 & 0.84 & 2.41 & 0.63 & 6.82 & 3.54 & 3.55 & 1.03 \\
\hline
\end{tabular}

${ }^{4}$ This analysis is similar to ones performed in comparable studies that failed to find three-way interactions between stimulus type, lag, and order of presentation. The interpretation of these planned comparisons performed in the absence of the appropriate interaction must be made with caution. 


\section{LEXICAL DECISION}
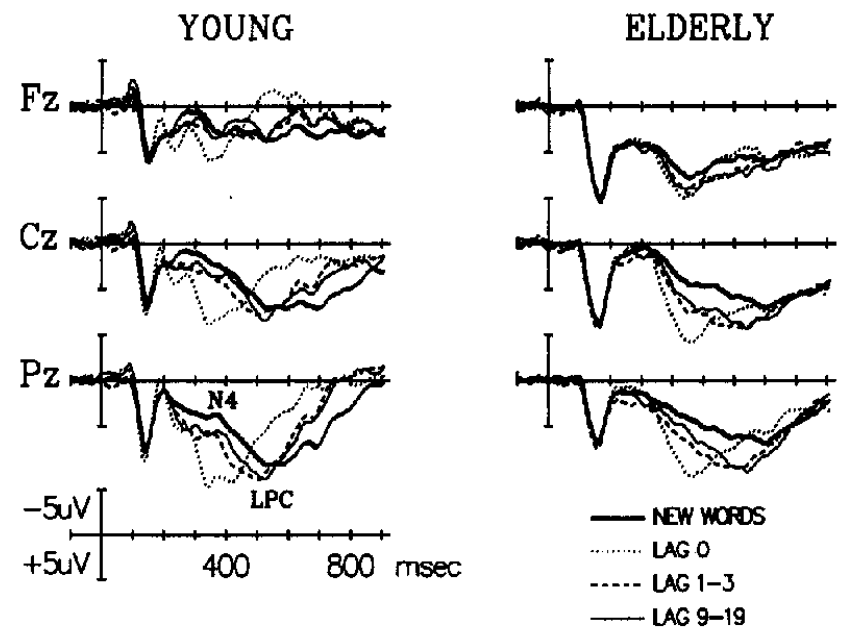

Figure 1. Grand average event-related potentials recorded from frontal $(\mathrm{Fz})$, central $(\mathrm{Cz})$, and parietal $(\mathrm{Pz})$ midline electrodes in young and elderly participants for words presented during Experiment 1 . The $\mathrm{N} 400$ (N4) and the late-positive component (LPC) are labeled. In this figure, negative is up; the vertical calibration bar shows the stimulus onset.

repetition were statistically comparable. Older adults again showed enhanced frontal positivity across all conditions compared with the young adults.

Mean amplitudes. The task requirement of responding to each stimulus resulted in large LPCs that overlapped with the $\mathrm{N} 400$, which was small and difficult to identify in the elderly. Instead of measuring peak latency and amplitude, ERP data were quantified by measuring mean amplitudes within two latency windows to capture the early (300-500 $\mathrm{ms})$ and late $(500-800 \mathrm{~ms})$ phases of the repetition effect. For the 300-500-ms interval, the main effects of stimulus type, $F(1,16)=33.46, p<.0001, M S E=1,528$, and repetition, $F(3,48)=12.90, p<.0001, M S E=525$, were significant. Mean amplitudes were greater for words than for nonwords and for repeated stimuli compared with new stimuli, similar to the RT results. A Stimulus Type $\times$ Age interaction was also seen, $F(1,16)=7.27, p<.05, M S E=$ 332 , reflecting the fact that young participants accounted for most of the difference between words and nonwords: young, $F(1,8)=30.27, p<.001, M S E=1,642$; elderly, $F(1,8)=$ $5.87, p<.05, M S E=218$. Electrode site interacted with repetition, $F(54,864)=9.96, p<.0001, M S E=9$, and age, $F(18,288)=7.52, p<.001, M S E=217$. The former observation indicated that the ERP repetition effect is minimal over frontal regions, intermediate at occipital and posterior temporal electrodes, and largest at parietal and central sites (see Figure 3). The latter finding reflects the greater positivity observed over frontal sites in the elderly for all conditions, whereas positive amplitudes at all other scalp locations were generally larger in the young. Additionally, the interaction between electrode and stimulus type was significant, $F(18,288)=2.94, p<.05, M S E=3$; the difference between words and nonwords was largest at frontal and central electrodes (i.e., Fz, F3/4, Cz, and C3/4). Subtraction waveforms (Figure 4) best illustrate this divergence between stimulus types. For the 500-800-ms interval, the main effect of repetition, $F(3,48)=9.03, p<.001$, $M S E=491$, was significant, as was the Repetition $\times$ Age interaction, $F(3,48)=4.90, p<.01, M S E=266$. The elderly continued to generate more positive ERPs to lag 1-3 and lag 9-19 items within this window, whereas the young did not.

To further explore the time course of these ERP repetition effects, we evaluated mean amplitudes within 100 -ms windows. Because repetition effects were negligible over frontal sites, only the central, parietal, temporal, and occipital leads were used (12 levels). In general, repetition enhanced positive amplitudes from $300-500 \mathrm{~ms}$ in the young adults and from $300-700 \mathrm{~ms}$ in the elderly adults (see Table 3). Contrasts between new and repeated stimuli and between repeated items at different lags are reported in the Appendix. For $300-400 \mathrm{~ms}$, the main effect of repetition, $F(3,48)=$ $12.49, p<.0001$, was modified by an interaction with age, $F(3,48)=6.16, p<.005$. The peak of the LPC to immediately repeated stimuli fell within this window for the young but was later for the elderly. For $400-500 \mathrm{~ms}$, the main effect of repetition, $F(3,48)=23.66, p<.0001$, was significant. For $500-600 \mathrm{~ms}$, both repetition, $F(3,48)=$ $8.72, p<.001$, and Repetition $\times$ Age, $F(3,48)=7.75, p<$ .001 , were significant. The elderly continued to generate enhanced LPCs to repeated stimuli, whereas the LPC to repeated items in the young had begun its return to baseline. This was also true for $600-700 \mathrm{~ms}$, Repetition $\times$ Age, $F(3$, $48)=7.75, p<.005$, in which the elderly generated greater positivities to lag 1-3 and lag 9-19 stimuli relative to new items. The persistent repetition, $700-800, F(3,48)=12.30$,

\section{LEXICAL DECISION}

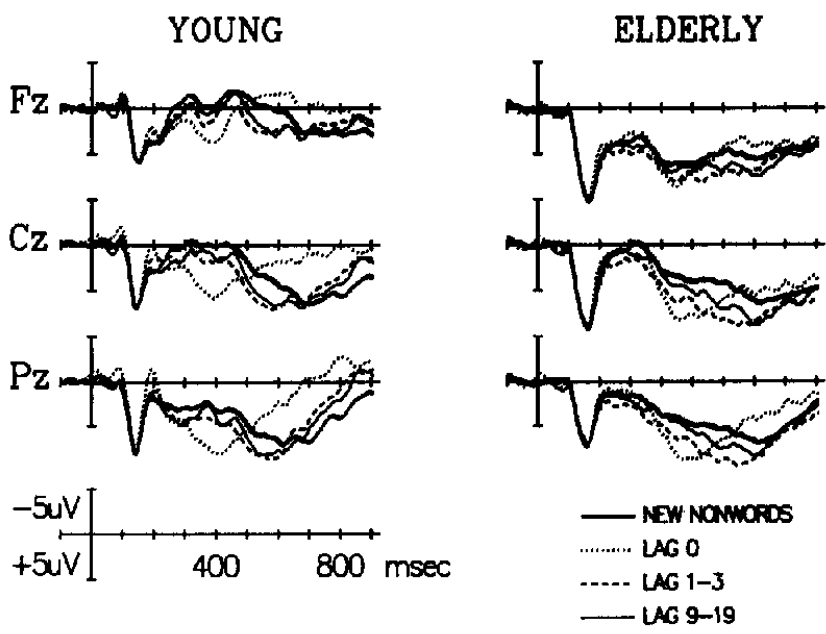

Figure 2. Grand average event-related potentials recorded from frontal (Fz), central $(\mathrm{Cz})$, and parietal $(\mathrm{Pz})$ midline electrodes in young and elderly participants elicited by nonwords presented during Experiment 1 . In this figure, negative is up; the vertical calibration bar shows the stimulus onset. 


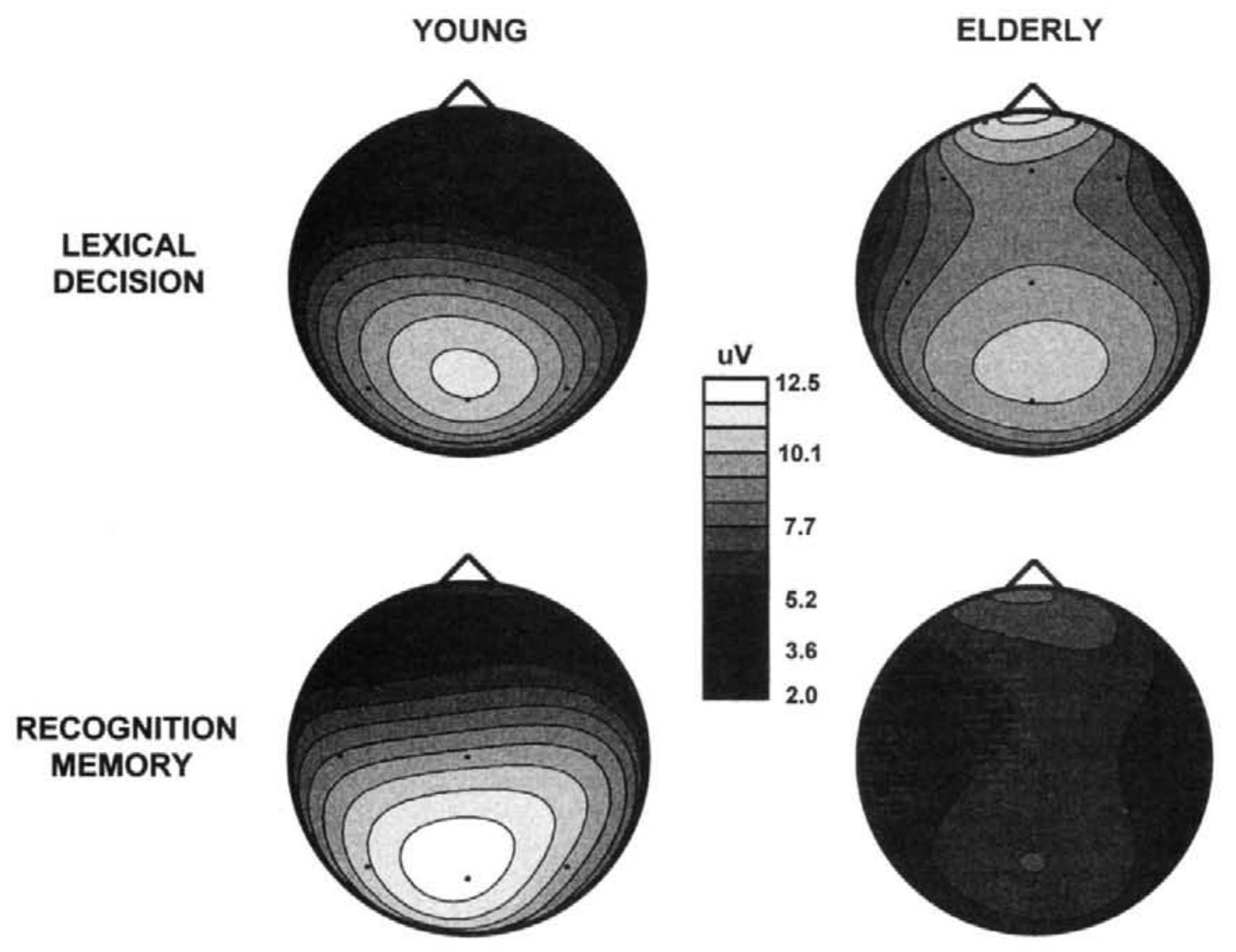

Figure 3. Topographic maps displaying the scalp voltage distribution of the late-positive component for delayed word repetitions (lag 9-19) in Experiment 1 (top) and Experiment 2 (bottom). Peak amplitude in the $400-700$-ms window was plotted as positive voltages $(\mu \mathrm{V})$ for 19 electrode sites. Young participants exhibited central-parietal maxima in both tasks. The elderly showed increased positivity at frontal sites relative to young participants, particularly for lexical decision, resulting in a more equal distribution across the scalp. Older participants generated significantly less positivity in the recognition memory task.

$p<.0001 ; 800-900, F(3,48)=6.10, p<.005$, and Repetition $\times$ Age, 700-800, $F(3,48)=5.31, p<.05$; $800-900, F(3,48)=3.53, p<.05$, effects in the latest windows reflected the return to baseline of the LPC to repeated items, particularly in young participants.

DIFFERENCE WAVES: NEW WORDS - NEW NONWORDS
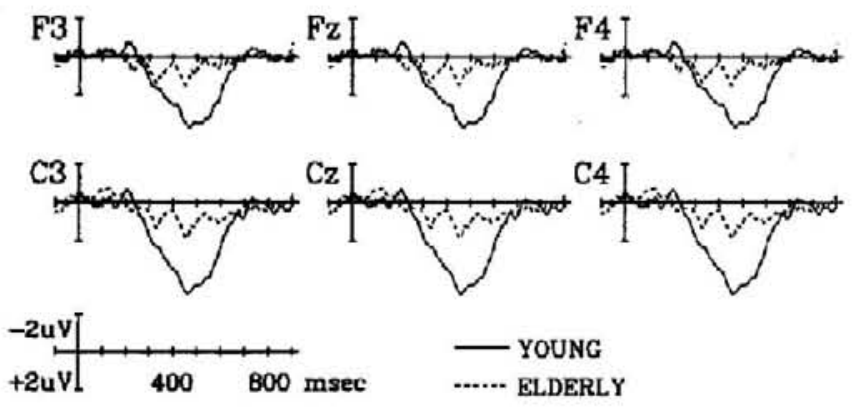

Figure 4. Subtraction waveforms (new words - new nonwords) at frontal $(\mathrm{F} 3, \mathrm{Fz}$, and $\mathrm{F} 4)$ and central $(\mathrm{C} 3, \mathrm{Cz}$, and $\mathrm{C} 4)$ sites for Experiment 1 (lexical decision), in which the difference between stimulus types was largest in young adults. In this figure, negative is up; the vertical calibration bar shows the stimulus onset.

\section{Discussion}

\section{Performance}

Age did not affect overall response time in the lexical decision task. All participants had substantially faster RTs when words were repeated at each of the three delays, with the largest priming effect for immediate repetitions. A number of other investigators have noted larger RT differences for the short-term component of word repetition priming than for the long-term component (Bentin \& Moscovitch, 1988; Forster \& Davis, 1984; Kersteen-Tucker, 1991; Scarborough et al., 1977). Nonword priming was significant at the two shorter delays and showed a trend toward significance at the longest lag, in accord with other reports of variable long-term nonword priming effects during lexical decision. For instance, nonword priming was observed only for lags 0 and 1 intervening items but not for lags 4 and 8 in one experiment (Kersteen-Tucker, 1991) and for lag 0 but not for lags 4 and 15 in another (Bentin \& Moscovitch, 1988). Conversely, Smith and Oscar-Berman (1990) found significant nonword priming with an average lag of 15 intervening items. When a secondary task was added to diminish the influence of episodic memory, word priming was reduced but still significant, whereas nonword 
Table 3

Mean Amplitude Measures (in $\mu \mathrm{V}$ ) and Standard Errors of the Mean for the Lexical Decision Task

\begin{tabular}{|c|c|c|c|c|c|c|c|c|}
\hline \multirow[b]{2}{*}{ Condition } & \multicolumn{2}{|c|}{$300-400$} & \multicolumn{2}{|c|}{$400-500$} & \multicolumn{2}{|c|}{$500-600$} & \multicolumn{2}{|c|}{$600-700$} \\
\hline & $M$ & $S E M$ & $M$ & $S E M$ & $M$ & $S E M$ & $M$ & $S E M$ \\
\hline \multicolumn{9}{|l|}{ Young } \\
\hline New & 2.27 & 0.34 & 3.01 & 0.34 & 4.87 & 0.37 & 4.84 & 0.36 \\
\hline Lag 0 & 5.76 & 0.44 & 5.81 & 0.36 & 2.96 & 0.31 & 0.84 & 0.26 \\
\hline Lag 1-3 & 3.49 & 0.33 & 4.72 & 0.35 & 6.07 & 0.34 & 4.02 & 0.32 \\
\hline Lag 9-19 & 3.12 & 0.33 & 3.78 & 0.33 & 5.51 & 0.35 & 4.31 & 0.30 \\
\hline \multicolumn{9}{|l|}{ Elderly } \\
\hline New & 1.61 & 0.23 & 2.76 & 0.24 & 3.70 & 0.23 & 4.26 & 0.25 \\
\hline Lag 0 & 2.58 & 0.23 & 6.52 & 0.30 & 6.02 & 0.25 & 4.19 & 0.23 \\
\hline Lag 1-3 & 2.94 & 0.24 & 4.84 & 0.26 & 6.53 & 0.27 & 6.75 & 0.26 \\
\hline Lag 9-19 & 2.56 & 0.21 & 4.08 & 0.25 & 5.57 & 0.27 & 6.24 & 0.28 \\
\hline
\end{tabular}

Note. Values are collapsed across words and nonwords and across central, parietal, temporal, and occipital electrodes.

priming was no longer observed (Smith \& Oscar-Berman, 1990). This suggests that repetition priming for words relies on an additional lexical or semantic factor not available for nonwords.

The percentage of priming data indicated that the elderly participants showed less priming for nonwords than for words, whereas this was not the case for young participants. One explanation could be that priming effects for words primarily draw upon mechanisms related to logogen-type models (Morton, 1969) or to facilitation within the perceptual representation system for visual word forms (Tulving \& Schacter, 1990), with a relatively small contribution from episodic factors. Conversely, retrieval of episodic memory traces may play a larger role in nonword priming because nonwords have no prior representation within the lexicon and no semantic content. The observation that older adults typically show a decline in recognition memory but relatively intact word priming abilities (Light, 1991), combined with the current finding of smaller repetition priming effects for nonwords in the elderly but not in the young, is consistent with the interpretation that nonword priming is more reliant on explicit factors than word priming. Additional support for this hypothesis is provided by the lack of nonword priming in the elderly at the longest delay, when recognition performance typically declines.

The PRS model hypothesizes that priming for new visual information such as nonwords, like priming for verbal material with preexisting representations, is mediated by modifications that occur in the relatively early stages of sensory processing (Tulving \& Schacter, 1990). If nonword priming is facilitated by entirely the same mechanism as word priming, then the degree of priming for the two stimulus types should not have differed in the elderly. Our results indicate that nonword priming in lexical decision relies on mechanisms outside the visual word form area favored by the PRS model. Long-term nonword priming effects are more commonly reported in perceptual identification (Feustel et al., 1983; Haist et al., 1991), suggesting that this paradigm may be a more "pure" measure of perceptual priming less "contaminated" by lexical or conceptual influences. Alzheimer's patients, who show major deficits in episodic and lexical-semantic memory, demonstrated intact nonword priming in perceptual identification (Keane, Gabrieli, Growdon, \& Corkin, 1994), lending support to this contention. The pronounceable nonwords used in the present study displayed phonological and orthographic similarities to words. Therefore, another possibility is that implicit memory for phonologically and orthographically legal nonwords is mediated by their sublexical elements. In support of this idea, perceptual identification priming occurred invariably for nonwords formed out of morphemic components, inconsistently for nonwords formed from syllabic components, and minimally for nonwords formed from pseudosyllabic components (Dorfman, 1993). Priming in a word judgment task was observed consistently for both morphemic and syllabic nonwords but not for pseudosyllabic nonwords (Dorfman, 1994).

All participants were very accurate in the lexical decision task, averaging fewer than $5 \%$ errors overall for a large set of low frequency words. Accuracy was higher for repeated stimuli than for new items, particularly for words. Error rates did not differ between young and elderly, corresponding with other reports of not only intact vocabulary in older adults but improved scores relative to young adults (Mitchell, 1989).

\section{ERPs}

In both young and older adults, the repetition of words and pronounceable nonwords produced a positive shift in the waveform that began at $300 \mathrm{~ms}$, similar to prior studies (Karayanidis et al., 1991, 1993). Immediate repetitions evoked the largest and earliest positive shift, analogous to the fastest RTs observed for the shortest lag. Older adults showed not only intact ERP repetition effects at all three lags but even greater differences between new and repeated items than the young adults. The onset of the effect was slightly delayed in the elderly and its duration prolonged, similar to previous results (Friedman, Hamberger, \& Ritter, 1993; Hamberger \& Friedman, 1992; Karayanidis et al., 1993). One question posed by these findings is why the ERP repetition effect was larger in the elderly. One possibility is that the task was easier for the young participants and hence performed more automatically. Using a semantic discrimination task in which responses to repeated items were not required, Friedman et al. (1993) found that the larger and longer lasting repetition effect in the elderly was primarily due to the enhanced positivity elicited by repeated items, with only small differences in responses to new stimuli. This enhancement was attributed to additional but inefficient processing of repeated stimuli in older adults. In the current study, the overall pattern of change with repetition was similar in the two groups for the $300-500-\mathrm{ms}$ interval, whereas the elderly continued to generate larger positive responses to repeated stimuli in the 500-800-ms window. The simplest explanation for this finding is that older adults took longer to fully process each stimulus, resulting in a longer latency for the LPC. In oddball paradigms, aging can delay the latency of P300 either with or without a concomi- 
tant slowing of RT (Pfefferbaum, Ford, Wenegrat, Roth, \& Kopell, 1984).

Across all conditions, the elderly generated greater positivity at frontal sites relative to young participants. Older participants exhibited a similar large frontal positivity in response to all stimuli presented in the visual recognition study of Nielsen-Bohlman and Knight (1995), suggesting the possibility that changes in prefrontal cortical activation are associated with alterations in memory processes in the elderly. However, stimulus repetition in Experiment 1 was incidental to the task, so any memory retrieval that occurred was not deliberately required. Hence, this frontal positivity may be related to increases in effort or sustained attention necessary for the elderly to perform at a high level.

There were no statistically reliable differences between the repetition effect for words and nonwords at any delay. Nonword ERP modulations have been reported previously, although one experiment did not obtain nonword repetition at long lags (average delay of $2.5 \mathrm{~min}$; Smith \& Halgren, 1987). A large, broad ERP repetition effect was obtained for immediately repeated nonwords that were orthographically and phonologically legal, whereas the effect for illegal nonwords was much smaller and temporally limited (Rugg \& Nagy, 1987). Likewise, legal nonwords elicit N400s, whereas illegal nonwords do not (Kutas \& Van Petten, 1994). These observations imply that participants perform a search of lexical-semantic memory if the stimuli are sufficiently similar to words and that the repetition of novel, difficult to encode items produces negligible ERP effects. A third study found nonword repetition effects at lag 6, although the onset was later than for words (Rugg, Doyle, \& Wells, 1995); our failure to observe this could have been due to a lack of statistical power. At present, our data suggested that ERP signatures of word and nonword repetition rely on at least some overlapping processes because the onset and magnitude of the two responses did not differ. Additional experiments are needed to confirm this possibility. We later raise the issue of differing hemispheric asymmetries for word and nonword priming, implying nonoverlapping processes as well.

Across all conditions in young participants, nonwords evoked greater negativity in the $300-600$-ms range than words, similar to other studies (Holcomb, 1993; Kounios \& Holcomb, 1994). This difference was largest at the anterior electrodes and substantially smaller in older adults. One conceivable explanation for the more negative-going wave to nonwords is that young participants engage in a more exhaustive search of the lexicon in an attempt either to find a matching entry or to integrate the item into a larger "context." Another possibility is that due to their greater lifetime exposure to verbal material, "nothing is new" for the elderly so that words and nonwords are processed similarly. This observation was not apparent from examining the participants' behavioral data alone.

\section{Experiment 2}

This experiment was designed to assess explicit memory systems by utilizing a continuous recognition task. The participants, repetition delays, and types of stimuli used were identical to Experiment 1 . The response requirement. was the only variable that differed, allowing a direct comparison between ERPs in the two studies. In a behavioral investigation of verbal recognition memory at short and long delays, age-related declines in performance occurred at lags outside the range of immediate (or primary) memory, which was defined as after four intervening items or $12 \mathrm{~s}$ after first presentation (Poon \& Fozard, 1980). In a picture recognition paradigm, older adults showed impairments in performance and decreases in LPC amplitude when pictures repeated at longer delays (Nielsen-Bohlman \& Knight, 1995). Because verbal recognition memory in the elderly is intact at short delays and impaired at long delays, we predicted a similar pattern of results for the ERP repetition effect. Further, we wished to examine whether the ERP effect is larger when repetition is integral to the task, as would be predicted if it were more closely related to conscious recollection (Smith, 1993), although the debate about the relationship of these electrophysiological measures to relative familiarity and incidental repetition priming continues. Participants were seated in a dim, soundattenuated booth. An asterisk was presented at the center of the screen to signal the start of each block. Then a series of words and nonwords was presented. Participants were told that although some items were not real words, this was not important. Participants pressed one button for new items and the other button for repeated items, regardless of whether the stimuli were words or nonwords. They were instructed to respond as quickly and as accurately as possible using their left and right thumbs. Hand use was counterbalanced across subjects. After two short practice blocks, the first of eight experimental blocks was presented.

\section{Results}

\section{Performance}

RTs are shown in Table 4. These means were computed from individual participant mean RTs for correct responses only. Significant main effects were found for stimulus type, $F(1,16)=9.67, p<.01$, and repetition, $F(3,48)=52.11$, $p<.0001$. RTs were faster to words than to nonwords and faster for repeated items (compared with new items) at lag 0 $(p<.0001)$ and lag 1-3 $(p<.06)$ but were slower at lag 9-19 $(p<.01)$. The older participants were primarily respon-

Table 4

Mean Reaction Times (in Milliseconds) for Recognition Memory Task

\begin{tabular}{|c|c|c|c|c|c|c|c|c|}
\hline \multirow[b]{3}{*}{ Condition } & \multicolumn{4}{|c|}{ Words } & \multicolumn{4}{|c|}{ Nonwords } \\
\hline & \multicolumn{2}{|c|}{ Young } & \multicolumn{2}{|c|}{ Elderly } & \multicolumn{2}{|c|}{ Young } & \multicolumn{2}{|c|}{ Elderly } \\
\hline & $M$ & $\overline{S E M}$ & $M$ & $\overline{S E M}$ & $M$ & $\overline{S E M}$ & $M$ & $S E M$ \\
\hline $\begin{array}{l}\text { New } \\
\text { Lag } 0 \\
\text { Lag 1-3 } \\
\text { Lag 9-19 }\end{array}$ & $\begin{array}{l}846.6 \\
668.5 \\
786.2 \\
817.5\end{array}$ & $\begin{array}{l}51.3 \\
43.3 \\
49.0 \\
41.5\end{array}$ & $\begin{array}{l}791.8 \\
683.8 \\
772.9 \\
888.6\end{array}$ & $\begin{array}{l}51.1 \\
54.6 \\
59.4 \\
62.9\end{array}$ & $\begin{array}{l}879.9 \\
674.6 \\
814.9 \\
896.0\end{array}$ & $\begin{array}{l}56.2 \\
35.8 \\
47.9 \\
53.3\end{array}$ & $\begin{array}{l}818.4 \\
686.0 \\
818.9 \\
943.7\end{array}$ & $\begin{array}{l}58.3 \\
58.8 \\
64.4 \\
70.9\end{array}$ \\
\hline
\end{tabular}


sible for the latter effect (see Table 4). An interaction between stimulus type and repetition was also observed, $F(3,48)=8.18, p<.005$; significant effects of repetition condition were found for both words, $F(3,48)=41.74, p<$ .0001 , and nonwords, $F(3,48)=50.50, p<.0001$. The interaction between age and repetition was significant, $F(3$, $48)=3.93, p<.05$. In young participants, planned comparisons showed that relative to new stimuli, RTs to repeated stimuli were faster at lag $0(p<.0001)$ and lag $1-3$ $(p<.06)$ but not at lag 9-19 $(p>.6)$. As for the young, older participants responded faster to immediate repetitions than to new items $(p<.0001)$. However, the elderly were not faster to respond to lag 1-3items $(p>.5)$, and they were slower for lag 9-19 stimuli $(p<.001)$ compared with new stimuli.

For the accuracy data, significant main effects of age, $F(1$, $16)=8.19, p<.05$, and repetition, $F(3,48)=20.07, p<$ .0001 , were obtained, as well as an interaction between these two variables, $F(3,48)=6.48, p<.05$. Overall, the elderly were less accurate than the young, and both groups made more errors as the lag increased (see Table 5). Separate ANOVAs for each lag demonstrated that older adults were less accurate at recognizing repeated stimuli than young adults, particularly at the longest delay, $F(1,16)=8.76, p<$ .01. Older participants also made more errors for immediate repetitions, $F(1,16)=4.79, p<.05$, with a trend toward less accurate recognition of lag $1-3$ items, $F(1,16)=3.63, p<.08$.

\section{ERPs}

Words. Grand average ERPs from young participants are illustrated in Figure 5. Repetition effects were larger, earlier in onset, and longer in duration for recognition compared with lexical decision. In older adults, conversely, repetition effects were smaller, later in onset, and shorter in duration for recognition (Figure 5) than lexical decision. The enhancement of frontal positivity in the elderly was still visible at $\mathrm{Fz}$, although it was not as pronounced at lateral frontal sites in this paradigm. The ERP repetition effect was relatively preserved in the elderly at lag 0 and lag 1-3 but was eliminated for lag 9-19 items, which elicited less positivity than new stimuli.

Nonwords. Figure 6 depicts the ERPs to nonwords from the midline electrodes in both groups. Once again, note that the elderly generated enhanced frontal positivity across all conditions compared with young participants. As in lexical decision, the consequences of repetition were comparable

Table 5

Error Rates (in Percentages) for the Recognition Memory Task

\begin{tabular}{|c|c|c|c|c|c|c|c|c|}
\hline \multirow[b]{3}{*}{ Condition } & \multicolumn{4}{|c|}{ Words } & \multicolumn{4}{|c|}{ Nonwords } \\
\hline & \multicolumn{2}{|c|}{ Young } & \multicolumn{2}{|c|}{ Elderly } & \multicolumn{2}{|c|}{ Young } & \multicolumn{2}{|c|}{ Elderly } \\
\hline & $M$ & SEM & $M$ & $S E M$ & $M$ & $S E M$ & $M$ & $S E M$ \\
\hline $\begin{array}{l}\text { New } \\
\text { Lag 0 } \\
\text { Lag 1-3 } \\
\text { Lag 9-19 }\end{array}$ & $\begin{array}{r}3.06 \\
2.42 \\
4.69 \\
11.05\end{array}$ & $\begin{array}{l}0.69 \\
0.69 \\
1.00 \\
2.78\end{array}$ & $\begin{array}{r}4.08 \\
4.68 \\
8.53 \\
26.80\end{array}$ & $\begin{array}{l}1.34 \\
1.63 \\
2.56 \\
6.33\end{array}$ & $\begin{array}{l}4.58 \\
1.85 \\
4.12 \\
8.15\end{array}$ & $\begin{array}{l}1.22 \\
0.76 \\
0.85 \\
2.50\end{array}$ & $\begin{array}{r}3.73 \\
5.01 \\
13.65 \\
29.59\end{array}$ & $\begin{array}{l}0.72 \\
0.83 \\
4.55 \\
7.03\end{array}$ \\
\hline
\end{tabular}

\section{RECOGNITION MEMORY}
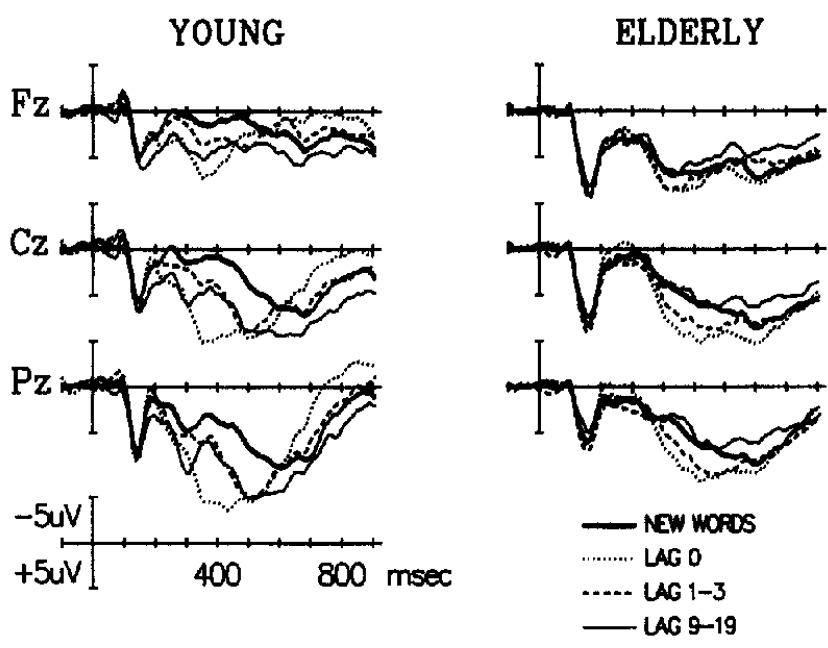

Figure 5. Grand average event-related potentials recorded from frontal $(\mathrm{Fz})$, central $(\mathrm{Cz})$, and parietal $(\mathrm{Pz})$ midline electrodes in young and elderly participants for words presented during Experiment 2 . In the elderly, the relative increase in frontal positivity (compared with the young) was minimal for lag 9-19 words, and the repetition effect did not occur at this delay. In this figure, negative is up; the vertical calibration bar shows the stimulus onset.

for the two stimulus types. The amplitude differences that were particularly pronounced in young participants during Experiment 1, however, were much smaller in Experiment 2. Namely, the finding that nonwords elicited more negativegoing waveforms across all conditions during lexical decision was a much smaller and more temporally restricted

\section{RECOGNITION MEMORY}

YOUNG
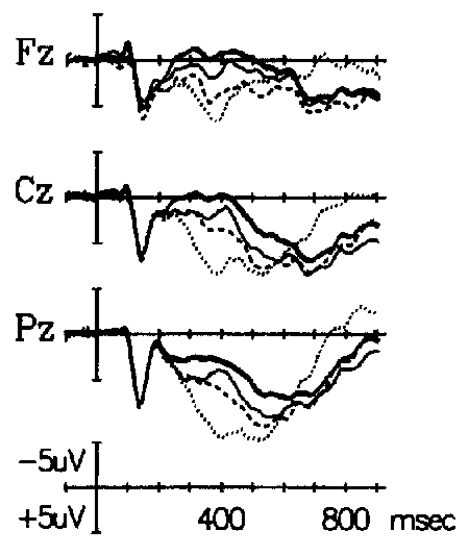

ELDERLY

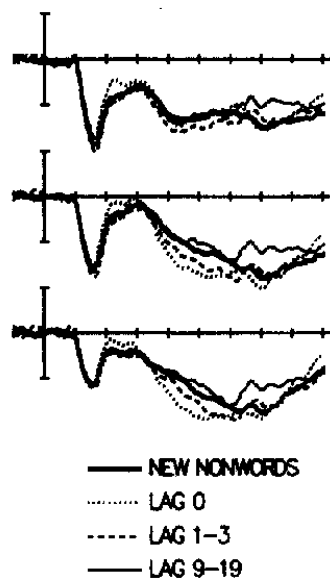

Figure 6. Grand average event-related potentials recorded from frontal (Fz), central $(\mathrm{Cz})$, and parietal $(\mathrm{Pz})$ midline electrodes for nonwords presented during Experiment 2 . The repetition effect for nonwords was similar to that for words in both young and elderly participants. In this figure, negative is up; the vertical calibration shows the stimulus onset. 
DIFFERENCE TAVES: NEW WORDS - NEW NONWORDS
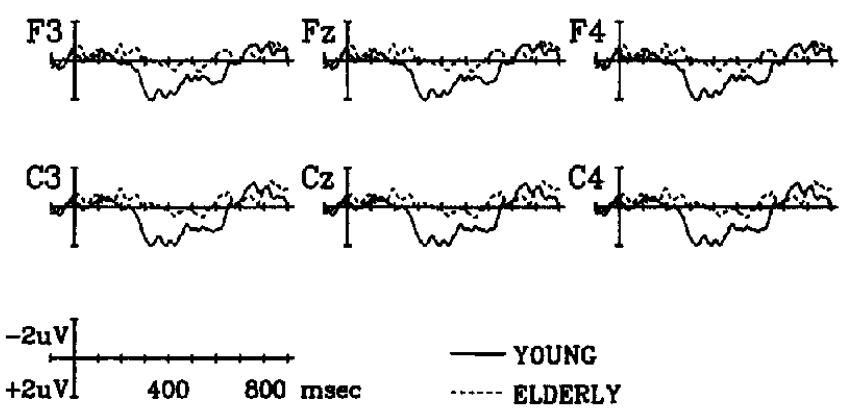

Figure 7. Subtraction waveforms (new words - new nonwords) at frontal (F3, Fz, and F4) and central (C3, Cz, and C4) sites in the recognition memory task (Experiment 2 ). The difference between stimulus types was much less pronounced in this paradigm (compare with Figure 5).

effect during continuous recognition, occurring only in the young. The subtraction waveforms for new words minus new nonwords (Figure 7) demonstrate that the divergence between stimulus types was much smaller than in the lexical decision task (compare with Figure 4).

Mean amplitudes. For the 300-500-ms interval, the main effects of stimulus type, $F(1,16)=5.13, p<.05$, $M S E=155$, and repetition, $F(3,48)=21.05, p<.0001$, $M S E=914$, were significant. Mean amplitudes were greater for words than for nonwords and for repeated items compared with new stimuli. All three main effects were modified by interactions with age. The Stimulus Type $\times$ Age result, $F(1,16)=6.31, p<.05, M S E=191$, reflected the fact that the young group was responsible for the difference between words and nonwords: young, $F(1,8)=9.37, p<.05$, $M S E=345$; elderly, $F(1,8)=0.04$. The interaction between repetition and age, $F(3,48)=9.53, p<.001$, $M S E=414$, was also followed by separate ANOVAs. These indicated that the young showed a significant repetition effect for this interval, $F(3,48)=23.51, p<.0001, M S E=$ 1,236 , whereas the elderly did not, $F(3,48)=2.67, p>.11$. The Electrode $\times$ Age, $F(18,288)=4.18, p<.01, M S E=$ 137 , and Electrode $\times$ Repetition interactions, $F(54,864)=$ $11.52, p<.0001, M S E=817$, were confirmed in the analysis of the normalized data. The former finding reflects the greater frontal positivity in the elderly for all conditions, whereas positive amplitudes at posterior scalp locations tended to be larger in the young. The latter observation indicated that the repetition effect for this interval was largest at central and parietal sites (see Figure 3). For the 500-800-ms interval, the Electrode $\times$ Repetition effect was marginal in the normalized data, $F(54,864)=2.02, p<.06$, $M S E=466$, whereas the Electrode $\times$ Stimulus Type interaction was not significant after normalization, $F(18$, 288) $=1.85, p>.11, M S E=231$. Most important, a significant Repetition $\times$ Age effect was observed, $F(3,48)=$ $6.64, p<.005, M S E=474$. Young adults continued to generate greater positivity to stimuli repeated at lags $1-3$ and 9-19, whereas ERPs from elderly participants were less positive going for stimuli repeated at lag 9-19 (see the Appendix).
Analyses of 100-ms time windows (Table 6) revealed that the onset of the ERP repetition effect occurred at $200 \mathrm{~ms}$ in the young but not until $400 \mathrm{~ms}$ in older adults. For the 200-300-ms window, the Repetition $\times$ Age interaction, $F(3$, 48) $=5.91, p<.01$, was significant. Repeated stimuli elicited greater positivity than first presentations in young participants, $F(3,24)=4.26, p<.05$, whereas the marginal effect of repetition in older participants, $F(3,24)=3.12$, $p<.07$, was due to smaller responses to immediate repeats. For $300-400-\mathrm{ms}$ interval, the main effect of repetition, $F(3$, $48)=13.43, p<.001$, and the Repetition $\times$ Age interaction, $F(3,48)=11.13, p<.001$, were significant. Similar to the prior interval, the repetition effect was significant for young participants, $F(3,24)=21.24, p<.001$, but not for the elderly, $F(3,48)=0.35$. For the $400-500$-ms window, both groups showed a repetition effect, although it was larger in the young. The main effect of repetition, $F(3,48)=36.02$, $p<.0001$, was modified by an interaction with age, $F(3,48)=5.23, p<.01$. For the $500-600-\mathrm{ms}$ interval, only the main effect of repetition was significant, $F(3,48)=$ $11.03, p<.001$. The Repetition $\times$ Age effect resumed during the $600-700-\mathrm{ms}, F(3,48)=5.76, p<.005$, and 700-800-ms windows, $F(3,48)=10.15, p<.001$, because the young still showed a repetition effect to long delay stimuli. In the elderly, however, the main effect of repetition was not significant in these intervals.

Hits versus misses. For lag 9-19 stimuli, the error rate was high enough in both groups to allow analysis of ERPs associated with incorrect responses. Figure 8 compares the ERPs elicited by stimuli repeated at the longest delay that were correctly remembered to those that were not recognized. For young participants, correctly remembered words resulted in a large LPC that was not observed when repeated words were not recognized. Nonwords, however, elicited comparable LPCs regardless of whether the item was correctly remembered. The amplitude of the LPC in the elderly was similar regardless of whether words and nonwords were recognized. Mean amplitudes for the 500800-ms window were measured for waveforms to lag 9-19 hits and for waveforms to lag 9-19 misses. These data were

Table 6

Mean Amplitude Measures (in $\mu V$ ) for the Recognition Memory Task

\begin{tabular}{|c|c|c|c|c|c|c|c|c|}
\hline \multirow[b]{2}{*}{ Condition } & \multicolumn{2}{|c|}{$300-400$} & \multicolumn{2}{|c|}{$400-500$} & \multicolumn{2}{|c|}{$500-600$} & \multicolumn{2}{|c|}{$600-700$} \\
\hline & $M$ & $S E M$ & $M$ & $S E M$ & $M$ & $S E M$ & $M$ & SEM \\
\hline \multicolumn{9}{|l|}{ Young } \\
\hline New & 2.04 & 0.32 & 2.52 & 0.26 & 4.54 & 0.27 & 5.01 & 0.27 \\
\hline Lag 0 & 7.08 & 0.48 & 8.78 & 0.39 & 7.75 & 0.32 & 4.37 & 0.22 \\
\hline Lag 1-3 & 3.79 & 0.38 & 5.68 & 0.37 & 7.30 & 0.37 & 5.74 & 0.31 \\
\hline Lag 9-19 & 4.08 & 0.35 & 4.73 & 0.34 & 6.81 & 0.37 & 6.39 & 0.31 \\
\hline \multicolumn{9}{|l|}{ Elderly } \\
\hline New & 2.29 & 0.18 & 3.57 & 0.23 & 4.96 & 0.23 & 5.74 & 0.29 \\
\hline Lag 0 & 2.57 & 0.26 & 6.32 & 0.32 & 7.33 & 0.32 & 6.59 & 0.35 \\
\hline Lag 1-3 & 2.71 & 0.20 & 4.65 & 0.27 & 6.53 & 0.28 & 6.17 & 0.31 \\
\hline Lag 9-19 & 2.22 & 0.20 & 3.22 & 0.26 & 4.58 & 0.21 & 4.78 & 0.24 \\
\hline
\end{tabular}

Note. Values are collapsed across words and nonwords and across central, parietal, temporal, and occipital electrodes. 


\section{LAG 9-19: YOUNG}

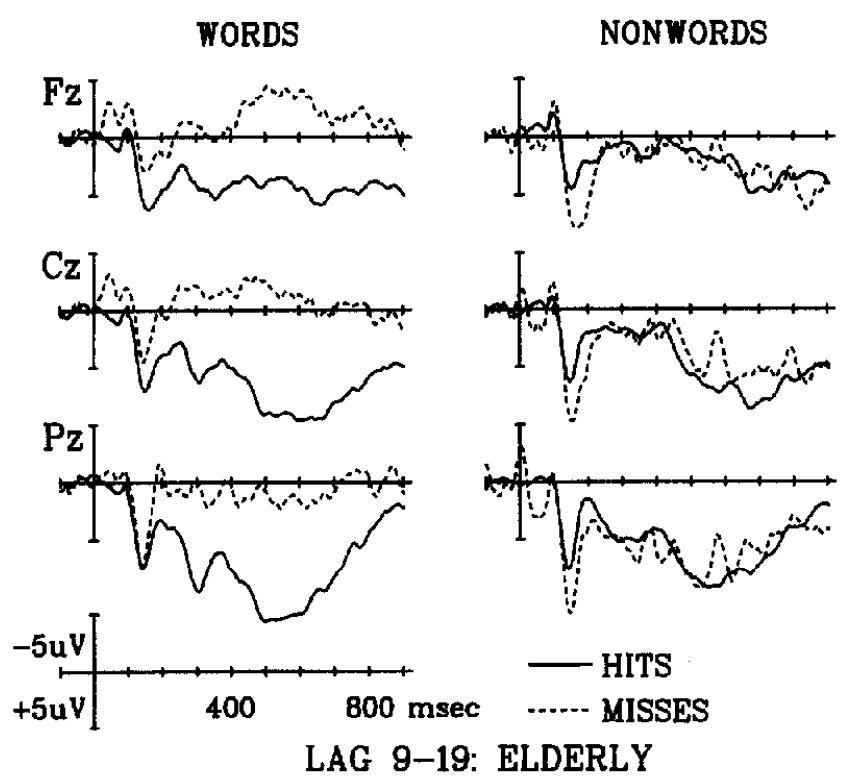

WORDS

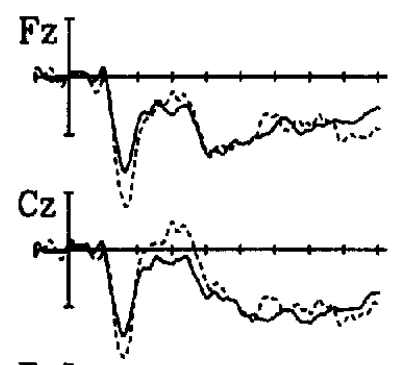

NONWORDS
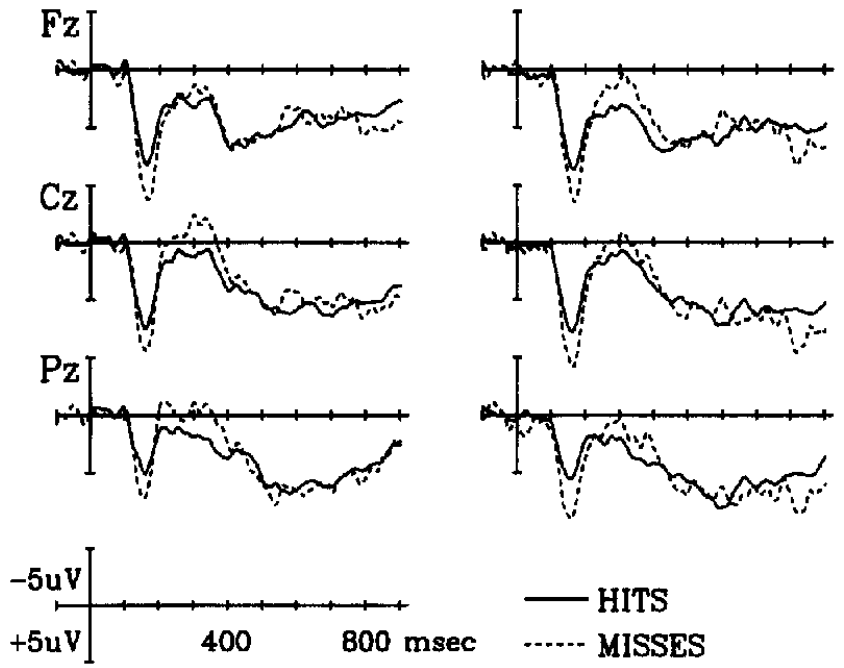

Figure 8. Grand average event-related potentials recorded from frontal $(\mathrm{Fz})$, central $(\mathrm{Cz})$, and parietal $(\mathrm{Pz})$ midline electrode sites, comparing the waveforms to correctly recognized lag 9-19 stimuli (hits, solid line) with the waveforms to lag 9-19 stimuli that were not recognized (misses, dashed line) for young and elderly in Experiment 2. In this figure, negative is up; the vertical calibration bar shows the stimulus onset.

analyzed by a four-way ANOVA with variables of age group, stimulus type, performance, and electrode. There was a trend for the LPC to hits $(5.0 \mu \mathrm{V})$ to be larger than to misses $(3.2$ $\mu \mathrm{V})$; marginal main effect of performance, $F(1,16)=3.87$, $p<.07, M S E=1,122$. Of greatest interest was the interaction between performance, stimulus type, and age, $F(1,16)=4.37, p=.05, M S E=590$. Tests for simple effects confirmed the above description: The main effect of performance was significant only for lag 9-19 words in the young, $F(1,8)=13.30, p<.01, M S E=2,237$, so that the LPC for hits $(6.2 \mu \mathrm{V})$ was greater than for misses $(1.0 \mu \mathrm{V})$.

\section{Task Comparisons}

To compare directly the differences between ERPs from Experiments 1 and 2, four-way ANOVAs with variables of age, stimulus type, repetition, and task were run for the 300-500-ms and 500-800-ms intervals for the Pz electrode. The Repetition $\times$ Age $\times$ Task interaction was significant for both windows: $300-500, F(3,48)=4.48, p<.05, M S E=$ $13 ; 500-800, F(3,48)=7.17, p<.005, M S E=28$. For young participants, the Repetition $\times$ Task interaction was significant for both $300-500, F(3,24)=3.92, p<.05$, $M S E=13$, repetition effect for lexical decision (LD), $F(3$, $24)=10.90, p<.005, M S E=56$; for recognition memory $(\mathrm{RM}), F(3,24)=46.25, p<.001, M S E=154$, and 500-800 intervals, $F(3,24)=9.87, p<.001, M S E=29$, LD, $F(3,24)=15.67, p<.001, M S E=73$ (with this difference due to less positivity for repeated items) $\mathrm{RM}, F(3$, $24)=4.30, p<.05, M S E=154$. Repetition $\times$ Task was significant for older adults in the 500-800-ms window, $F(3$, $24)=6.25, p<.01, M S E=30$; LD, $F(3,24)=7.11, p<$ $.005, M S E=25 ; \mathrm{RM}, F(3,24)=3.42, p<.07, M S E=25$. These interactions confirmed the previous observations about larger repetition effects for the young during recognition memory and for the elderly during lexical decision. For 300-500 ms, the significant Stimulus Type $\times$ Task interaction, $F(1,16)=9.07, p<.01, M S E=35$, indicated that the lexical decision task resulted in larger amplitude differences between words and nonwords than the continuous recognition paradigm. Finally, for $500-800 \mathrm{~ms}$, the main effect of task, $F(1,16)=8.96, p<.01, M S E=154$, and the Repetition $\times$ Task interaction, $F(3,48)=8.06, p<.001$, $M S E=95$, were both due to larger LPCs and greater repetition effects for young participants in Experiment 2.

Subtraction waveforms were computed for individual participants to examine old-new differences and were then analyzed to determine whether any hemispheric asymmetries in the repetition effect were visible across tasks. The 16 lateral electrodes were divided into eight left and eight right hemisphere leads and analyzed by five-way ANOVAs with variables of age, stimulus type, repetition, hemisphere, and task. Of greatest interest in the $300-500-\mathrm{ms}$ window was the significant Hemisphere $\times$ Stimulus Type $\times$ Task interaction $F(1,16)=7.35, p<.05, M S E=5$. The Hemisphere $\times$ Stimulus Type interaction was significant for lexical decision, $F(1,16)=17.67, p<.001, M S E=9$, but not for recognition, $F(1,16)=0.66$ (confirmed in the analysis of normalized data). The old-new difference waves for words and nonwords (Figure 9) display the repetition effect at four pairs of lateral electrodes. These ERPs were collapsed across lags, and all participants were included in the grand average because age did not influence the response. For lexical decision (Figure 9, top), the repetition effect was larger over the left hemisphere for words, $F(1,16)=5.91, p<.05$, $M S E=5$, but over the right hemisphere for nonwords, $F(1$, $16)=19.78, p<.001, M S E=4$. For recognition memory, (Figure 9, bottom), conversely, no hemispheric asymmetries were observed for either words or nonwords. 


\section{LEXICAL DECISION}
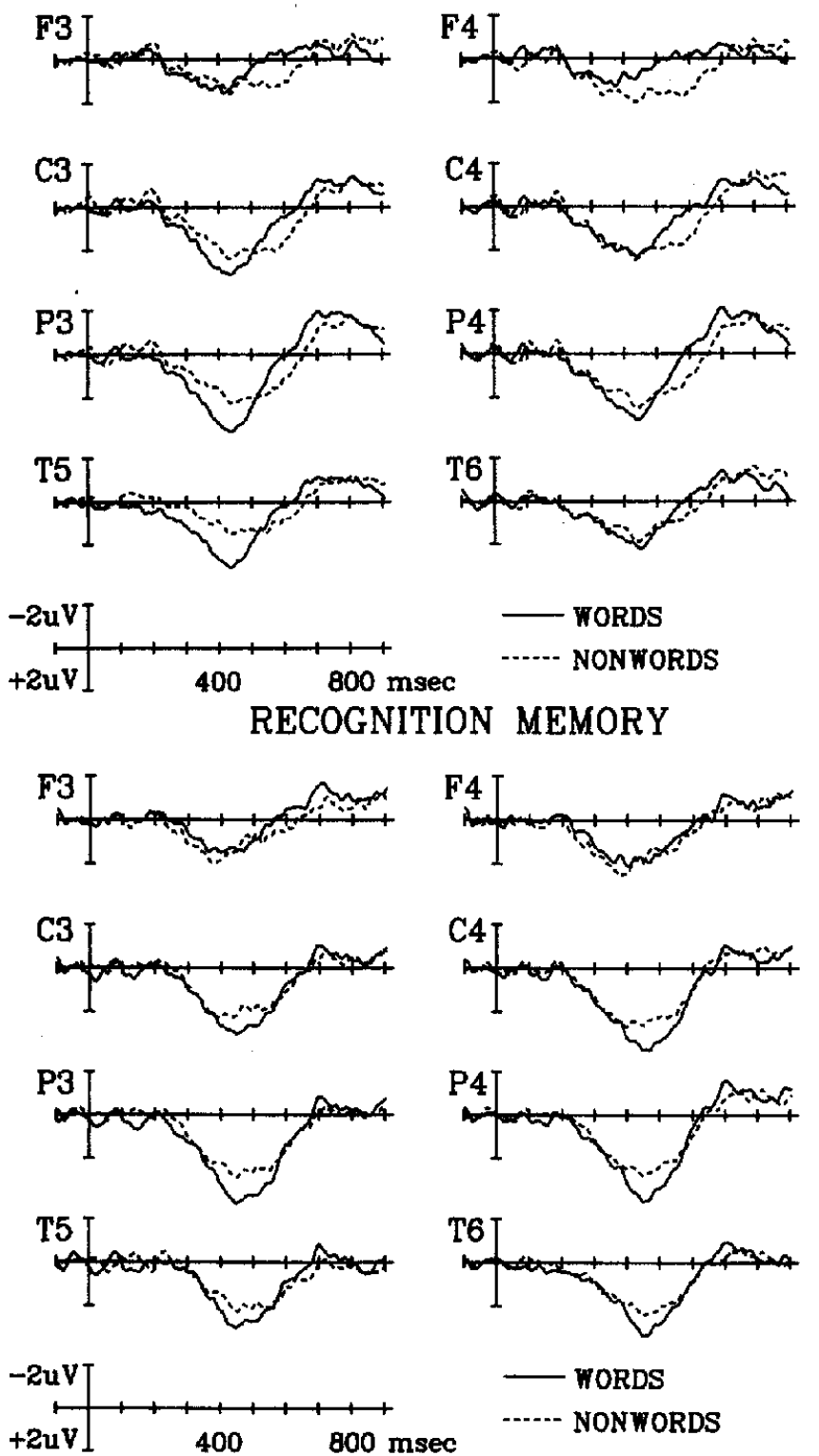

- WORDS

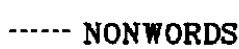

Figure 9. Old-new subtraction waveforms for words and nonwords in Experiment 1 (lexical decision task) and Experiment 2 (recognition memory task) display the repetition effect at four pairs of lateral electrodes (frontal [F3 and F4], central [C3 and C4], parietal [P3 and P4], and posterior temporal [T5 and T6]). These old - new differences were collapsed across the three lags. All 18 participants were included in the grand average. The vertical calibration bar shows the stimulus onset.

\section{Discussion}

\section{Performance}

In the recognition memory task, both groups responded more quickly to words than to nonwords, a finding that held across all four conditions but was most pronounced at the longest delay. Although participants were not less accurate at identifying repeated nonwords, they could have used different recollective mechanisms or strategies to recognize the two stimulus types, as suggested by the behavioral study of Gardiner and Java (1990). Word and nonword recognition was tested in young adults at a 24-hr retention interval. On the basis of two-process models of recognition memory, items can be recognized on the basis of increased familiarityrelative perceptual fluency ("know," or K) or elaboration of the original context ("remember," or R). Participants were instructed to give $\mathbf{R}$ (conscious recollection of prior occurrence) and $\mathrm{K}$ (recognition without any recollective experience) judgments on study items and foils (Gardiner \& Java, 1990). Nonwords were associated with a greater proportion of $\mathrm{K}$ responses and a smaller proportion of $\mathrm{R}$ responses in comparison to words, indicating that participants were less reliant on conscious recollection in their recognition of nonwords. Hence, nonword recognition in the present study may be based on relative familiarity to a greater extent than word recognition, an issue that will recur in the discussion of long-delay ERP effects.

As the length of the repetition delay increased, all participants became less accurate at recognizing repeated stimuli. Aging decreased recognition performance overall, with accuracy at the longest delay showing the greatest decline. Similar to Poon and Fozard (1980), there was no age difference in the percentage of correctly identified new items. By lag 1-3, the elderly tended to make more errors than the young, and this difference was significant at the longest delay, reflecting a decline in performance for items repeated outside the range of immediate memory. Differences between young and elderly adults were observed in the pattern of RTs to repeated stimuli in comparison to new stimuli. Both young and older participants were faster in responding to immediately repeated stimuli. For lag 1-3, young people were still faster, but the elderly were not. There was no difference between RTs to new and lag 9-19 items for the young. However, the RTs of the elderly were slower at the longest lag, suggesting a weakened memory trace that made retrieval of these items more difficult.

\section{ERPs}

In general, the ERPs in the explicit memory paradigm resembled the waveforms from Experiment 1 . The repetition of words and nonwords again elicited a positive shift in comparison to first presentations. The relative size of the repetition effect in the two groups and its pattern across lags, however, were different from those observed in the lexical decision task. Young people showed greater ERP repetition effects for recognition memory than for lexical decision, supporting the idea that this electrophysiological phenomenon is related to deliberate recollection (Smith, 1993). However, older adults showed the converse pattern: more pronounced ERP effects for lexical decision, in which repetition was incidental to the task. In support of the behavioral literature on age-related declines in explicit memory, the ERP repetition effect in the explicit task was smaller in the elderly than in the young, particularly at the longest delay. 
The positive-going shift related to repetition began at 200 $\mathrm{ms}$ and continued through $700 \mathrm{~ms}$ when young participants were deliberately recognizing repeated stimuli in this task, similar to other studies (Paller \& Kutas, 1992; Rugg \& Nagy, 1989; Smith, 1993). In comparison to young adults, the onset of the effect was delayed in the elderly and its duration was shorter, limited to the $400-600-\mathrm{ms}$ range. ERPs to lag 9-19 items tended to be less positive than ERPs to new items, a finding that was confirmed in a preliminary report (Mark, Rugg, Roberts, \& Gilchrist, 1995). In an earlier study of continuous verbal recognition, a dissociation between behavioral and ERP measures was described (Friedman, Berman, \& Hamberger, 1993). Although the elderly recognized fewer words repeated at the longest delay, they still showed an ERP repetition effect at this lag.

Parallel to their decline in performance at long delays, the elderly failed to show an ERP repetition effect at lag 9-19, even for correctly remembered items. For young participants, the accuracy of response at lag 9-19 had differential effects on the ERPs to words and nonwords. Correctly remembered words elicited a large LPC that was not observed when repeated words were not recognized. This result contrasts with the finding of Bentin et al. (1992), who reported a repetition effect even when participants did not remember repeated words. Nonwords, however, elicited comparable ERPs whether the item was correctly remembered. Although young participants were equally accurate at recognizing the two stimulus types, the quality or strength of the memory trace may have been weaker for nonwords. One explanation for this could be that the young adults based a greater proportion of their nonword recognition judgments on relative familiarity than on conscious recollection, whereas the converse may have been true for word recognition (Gardiner \& Java, 1990). Because K responses to correctly remembered words were associated with smaller LPCs than $R$ responses (Smith, 1993), a similar phenomenon might be true for nonwords. The amplitude of the LPC in the elderly was similar regardless of whether words and nonwords were recognized, suggesting that they may have used similar familiarity-based cues for both stimulus types. Another possibility is that young people responded to words and nonwords with varying degrees of confidence. P300 in signal detection paradigms is directly correlated with participant's confidence in their responses (Paul \& Sutton, 1972; Squires, Hillyard, \& Lindsay, 1973). Hence, the young could have responded more confidently to lag 9-19 words than to lag 9-19 nonwords, whereas the elderly may not have been confident in any of their decisions at the longest delay.

No other study, to our knowledge, has examined nonword ERP modulations during recognition memory tasks. Both short-term and long-term effects were observed in young participants. Although nonwords repeated at the longest delay appeared to produce a smaller repetition effect than words, this apparent variation did not approach significance. No other statistically reliable differences between the repetition effect for words and nonwords were observed at any delay. This was also true for elderly adults, whose waveforms looked remarkably similar for words and nonwords.

\section{General Discussion}

The present ERP results contribute to the behavioral literature on memory and aging in four major realms. First, in line with previous findings, these experiments provided behavioral evidence of intact implicit but impaired explicit memory in the elderly. ERPs provided additional confirmation of this finding at the level of time-locked, synchronized neuronal activity. Hence, both behavioral evidence and electrophysiological evidence of the implicit-explicit dissociation were obtained from older adults. Second, ERP data demonstrated that young people processed words and nonwords in a more differential fashion than the elderly. This was not apparent from examining either RTs or error rates. Third, ERP data revealed that the repetition effect in lexical decision engages left hemisphere processes to a greater extent for words but right hemisphere mechanisms for nonwords. Finally, the increase in frontal positivity in the elderly may reflect a greater engagement of attentional systems, suggesting that older participants had to exert greater effort to perform at a comparable level to the young (i.e., in lexical decision, in which behavioral performance was similar in both groups).

\section{Task Differences in Word and Nonword Processing}

The present experiments demonstrated differences in the electrophysiological responses to words and nonwords that were sensitive to whether the stimuli were processed for their lexicality or for their status as new or old. The effect of stimulus type in the lexical task was larger than that observed in the recognition task. Although the general pattern of the repetition effect during lexical decision did not vary between words and nonwords, the overall amplitude of the waveform between $300-600 \mathrm{~ms}$ was more negativegoing for nonwords, particularly in the young. This time frame overlaps with ERP components related to lexical search, integration, and context updating. In the elderly, the differences between word and nonword waveforms were less marked and were primarily due to smaller LPCs to nonwords. The overall amplitude differences between stimulus types were less pronounced in the recognition memory task, when attention was focused on encoding and retrieval rather than on lexicality. Words and nonwords were processed more similarly when they had to be remembered.

Further evidence for processing differences between words and nonwords during lexical decision was derived from the pattern of hemispheric asymmetries in this task. The repetition effect for words was larger over the left cerebral hemisphere, as might be expected if priming for verbal material is based on abstract lexical representations. On the other hand, the repetition effect for nonwords was larger over the right hemisphere, replicating the recent result of Doyle, Rugg, and Wells (1996). Form-specific representations are encoded more effectively in the right hemisphere, indicating that priming on the basis of visual forms may be lateralized to the right (Marsolek, Kosslyn, \& Squire, 1992). Because legal nonwords do not have abstract lexical representations as entire units, merely as their sublexical ele- 
ments, nonword priming may be more reliant on form-based mechanisms that manifest as a larger ERP effect over the right hemisphere. This is not to imply that no lexicalsemantic search was occurring for nonwords, merely that nonwords may rely on the right hemisphere priming mechanisms to a greater extend than words. The time course of this asymmetry $(300-500 \mathrm{~ms})$ was too late to reflect a purely perceptual process. Neuropsychological, positron emission tomography and ERP results have suggested that both left and right posterior cortical areas are important for visual word priming (Buckner et al., 1995; Carlesimo, Fadda, Sabbadini, \& Caltagirone, 1994; Gabrieli, Fleischman, Keane, Reminger, \& Morrell, 1995; Squire et al., 1992; Swick \& Knight, 1995).

No such left-right divergence was observed for word and nonword repetition in the explicit memory task, although others have reported old-new differences for words to be greater over the left than the right (Paller \& Kutas, 1992; Rugg \& Doyle, 1992).

\section{Aging and ERP Indices of Stimulus Repetition}

The ERP repetition effect in the elderly, like behavioral performance, was intact in an implicit task but impaired in an explicit memory task. An important issue to consider is whether this ERP effect indexes the same underlying processes in the two experiments. Bentin et al. (1992) postulated that LPC amplitude was sensitive to the strength of the episodic memory trace in both explicit and implicit memory tests. This implies that a decay in trace strength over time would be reflected by a decrease in LPC amplitude. The difficulty with the trace strength hypothesis lies in the large repetition effects exhibited by older participants in the implicit but not the explicit task. These ERP modulations may well reflect episodic memory access, but they did not appear to be related to trace strength in a linear fashion. The overlap of response-related processes, including the influence of confidence on P300, makes interpretation more difficult. The elderly most likely gave more confident responses for lexical decision than for recognition memory, correlating with their ERPs. For the young, conversely, repetition effects were larger for recognition, which was presumably the more difficult task (on the basis of their longer RTs and higher error rates). Factors other than confidence appear to influence this ERP response. Additional experiments that obtain confidence measures and remember-versus-know responses from older participants will elucidate these issues.

One possible issue in directly comparing the repetition effects from the two experiments is that lexical decision requires the same response for new and repeated items, whereas the recognition task mandates different responses. A previous study (Rugg, Brovendani, \& Doyle, 1992) removed this confound in a memory paradigm with words that repeated multiple times, both within and between blocks. Differential responses were required only for the former (i.e., participants replied "new" for words appearing the first time in a given block, but they may have responded both "new" and "old" to these same words in the previous block). ERP effects were qualitatively similar for both conditions.

Recognition memory performance varies according to normative word frequency, with more accurate responses to low frequency words. Another proposed explanation for the LPC repetition effect relies on this advantage for low frequency words and on the concept of relative familiarity (Rugg, 1990; Rugg \& Doyle, 1992). Uncommon words have a low level of baseline familiarity. Hence, repetition of low frequency words produces a greater increase in relative familiarity than high frequency words, as well as a larger ERP effect. Pronounceable nonwords have a baseline familiarity of zero but yet resemble real words. Nonword repetition should increase the item's relative familiarity to an even greater extent than the repetition of low frequency words, resulting in larger LPCs. However, the LPCs to nonwords were smaller than to words in young and old adults, particularly for lexical decision.

Instead of being a direct reflection of repetition priming, other research has suggested that this positive ERP shift may more closely measure "conscious recollection" (Paller \& Kutas, 1992; Smith, 1993). The strongest test of this theory would come from investigations of amnesia and other neurological syndromes. The occurrence of ERP repetition effects in memory-impaired participants during lexical decision but not during recognition would indicate that some portion of the effect must be related to implicit memory, whether that is conceptualized as reflecting relative familiarity, the temporary activation of a logogen, or more efficient processing in the visual word form area. In the present experiment we did not find a specific ERP component that could be directly related to priming in the absence of episodic influences. However, the preservation of the longdelay repetition effect in the elderly for lexical decision but not for recognition memory suggests that one portion of this ERP modulation can be linked with indirect memory. Another finding in support of this contention is that patients with damage to temporal-occipital cortex were impaired in both behavioral and ERP correlates of word repetition (Swick \& Knight, 1995). Hence, this electrophysiological effect appears to consist of processes related to both explicit and implicit aspects of stimulus repetition. The relative contributions of these two types of memory may vary on the basis of task requirements and age. Further study of these ERP effects can help elucidate the nature and time course of priming and recognition processes in both young and older adults. The current experiments took a step in this direction by demonstrating that the consequences of aging dissociate both ERP and behavioral measures of implicit and explicit memory.

\section{References}

Bentin, S., McCarthy, G., \& Wood, C. C. (1985). Event-related potentials, lexical decision and semantic priming. Electroencephalography and Clinical Neurophysiology, 60, 343-355.

Bentin, S., \& Moscovitch, M. (1988). The time course of repetition effects for words and unfamiliar faces. Joumal of Experimental Psychology: General, 117, 148-160.

Bentin, S., Moscovitch, M., \& Heth, I. (1992). Memory with and 
without awareness: Performance and electrophysiological evidence of savings. Journal of Experimental Psychology: Learning, Memory, and Cognition, 18, 1270-1283.

Bentin, S., \& Peled, B. S. (1990). The contribution of task-related factors to ERP repetition effects at short and long lags. Memory \& Cognition, 18, 359-366.

Besson, M., Kutas, M., \& Van Petten, C. (1992). An event-related potential (ERP) analysis of semantic congruity and repetition effects in sentences. Journal of Cognitive Neuroscience, 4, 132-149.

Bowers, J. S. (1994). Does implicit memory extend to legal and illegal nonwords? Journal of Experimental Psychology: Learning, Memory, and Cognition, 20, 534-549.

Buckner, R. L., Petersen, S. E., Ojemann, J. G., Miesin, F. M., Squire, L. R., \& Raichle, M. E. (1995). Functional anatomical studies of explicit and implicit memory retrieval tasks. Journal of Neuroscience, 15, 12-29.

Carlesimo, G. A., Fadda, L., Sabbadini, M., \& Caltagirone, C. (1994). Visual repetition priming for words relies on access to the visual input lexicon: Evidence from a dyslexic patient. Neuropsychologia, 32, 1089-1100.

Cermak, L. S., Chandler, K., \& Wolbarst, L. (1985). The perceptual priming phenomenon in amnesia. Neuropsychologia, 23, 615622.

Chiarello, C., \& Hoyer, W. J. (1988). Adult age differences in implicit and explicit memory: Time course and coding effects. Psychology and Aging, 3, 358-366.

Clarke, R., \& Morton, J. (1983). Cross-modality facilitation in tachistoscopic word presentation. Quarterly Journal of Experimental Psychology, 35A, 79-96.

Davis, H. P., Cohen, A., Gandy, M., Colombo, P., Van Dusseldorp, G., Simolke, N., \& Romano, J. (1990). Lexical priming deficits as a function of age. Behavioral Neuroscience, 104, 288-297.

Dorfman, J. (1993, November). Further evidence for sublexical components in implicit memory for novel words. Poster presented at the annual meeting of the Psychonomic Society, Washington, DC.

Dorfman, J. (1994). Sublexical components in implicit memory for novel words. Journal of Experimental Psychology: Learning, Memory, and Cognition, 20, 1108-1125.

Doyle, M. C., Rugg, M. D., \& Wells, T. (1996). A comparison of the electrophysiological effects of formal and repetition priming. Psychophysiology, 33, 132-147.

Feustel, T. C., Shiffrin, R. M., \& Salasoo, A. (1983). Episodic and lexical contributions to the repetition effect in word identification. Joumal of Experimental Psychology: General, 112, 309346.

Forbach, G. B., Stanners, R. F., \& Hochhaus, L. (1974). Repetition and practice effects in a lexical decision task. Memory \& Cognition, 2, 337-339.

Forster, K. I., \& Davis, C. (1984). Repetition priming and frequency attenuation in lexical access. Journal of Experimental Psychology: Learning, Memory, and Cognition, 10, 680-698.

Francis, W. N., \& Kučera, H. (1982). Frequency analysis of English usage: Lexicon and grammar. Boston: Houghton Mifflan.

Friedman, D. (1990). ERPs during continuous recognition memory for words. Biological Psychology, 30, 61-87.

Friedman, D., Berman, S., \& Hamberger, M. (1993). Recognition memory and ERPs: Age-related changes in young, middle-aged, and elderly adults. Joumal of Psychophysiology, 7, 181-201.

Friedman, D., Hamberger, M., \& Ritter, W. (1993). Event-related potentials as indicators of repetition priming in young and older adults: Amplitude, duration, and scalp distribution. Psychology and Aging, 8, 120-125.

Friedman, D., Hamberger, M., Stern, Y., \& Marder, K. (1992).
Event-related potentials (ERPs) during repetition priming in Alzheimer's patients and young and older controls. Joumal of Clinical and Experimental Neuropsychology, 14, 448-462.

Gabrieli, J. D. E., Fleischman, D. A., Keane, M. M., Reminger, S. L., \& Morrell, F. (1995). Double dissociation between memory systems underlying explicit and implicit memory in the human brain. Psychological Science, 6, 76-82.

Gandiner, J. M., \& Java, R. I. (1990). Recollective experience in word and nonword recognition. Memory \& Cognition, 18, 23-30.

Gordon, B. (1988). Preserved learning of novel information in amnesia: Evidence for multiple memory systems. Brain and Cognition, 7, 257-282.

Graf, P., Squire, L. R., \& Mandler, G. (1984). The information that amnesic patients do not forget. Joumal of Experimental Psychology: Learning, Memory, and Cognition, 10, 164-178.

Haist, F., Musen, G., \& Squire, L. R. (1991). Intact priming of words and nonwords in amnesia. Psychobiology, 19, 275-285.

Halgren, E., \& Smith, M. E. (1987). Cognitive evoked potentials as modulatory processes in human memory formation and retrieval. Human Neurobiology, 6, 129-139.

Hamberger, M., \& Friedman, D. (1992). Event-related potential correlates of repetition priming and stimulus classification in young, middle-aged, and older adults. Joumal of Gerontology: Psychological Sciences, 47, P395-P405.

Hillyard, S. A., \& Picton, T. W. (1987). Electrophysiology of cognition. In F. Plum (Ed.), Handbook of physiology: The nervous system (Vol. V, pp. 519-584). Bethesda, MD: American Physiological Society.

Holcomb, P. J. (1993). Semantic priming and stimulus degradation: Implications for the role of the $\mathrm{N} 400$ in language processing. Psychophysiology, 30, 47-61.

Jacoby, L. L., \& Dallas, M. (1981). On the relation between autobiographical memory and perceptual learning. Journal of Experimental Psychology: General, 110, 306-340.

Jasper, H. H. (1958). Report of the committee on methods of clinical examination in electroencephalography. Electroencephalography and Clinical Neurophysiology, 10, 371-375.

Java, R. I., \& Gardiner, J. M. (1991). Priming and aging: Further evidence of preserved memory function. American Journal of Psychology, 104, 89-100.

Karayanidis, F., Andrews, S., Ward, P. B., \& McConaghy, N. (1991). Effects of inter-item lag on word repetition: An eventrelated potential study. Psychophysiology, 28, 307-318.

Karayanidis, F., Andrews, S., Ward, P. B., \& McConaghy, N. (1993). Event-related potentials and repetition priming in young, middle-aged and elderly normal subjects. Cognitive Brain Research, 1, 123-134.

Keane, M. M., Gabrieli, J. D. E., Growdon, J. H., \& Corkin, S. (1994). Priming in perceptual identification of pseudowords is normal in Alzheimer's disease. Neuropsychologia, 32, 343-356.

Kersteen-Tucker, Z. (1991). Long-term repetition priming with symmetrical polygons and words. Memory \& Cognition, 19, $37-43$.

Kounios, J., \& Holcomb, P. J. (1994). Concreteness effects in semantic processing: ERP evidence supporting dual-coding theory. Journal of Experimental Psychology: Learning, Memory, and Cognition, 20, 804-823.

Kutas, M., \& Van Petten, C. (1988). Event-related brain potential studies of language. In P. K. Ackles, J. R. Jennings, \& M. G. H. Coles (Eds.), Advances in psychophysiology (Vol. 3, pp. 139187). Greenwich, CT: JAI Press.

Kutas, M., \& Van Petten, C. (1994). Psycholinguistics electrified: Event-related brain potential investigations. In $\mathbf{M}$. Gernsbacher 
(Ed.), Handbook of psycholinguistics (pp. 83-143). New York: Academic Press.

Light, L. L. (1991). Memory and aging: Four hypotheses in search of data. Annual Review of Psychology, 42, 333-376.

Light, L. L., \& Singh, A. (1987). Implicit and explicit memory in young and older adults. Journal of Experimental Psychology: Learning, Memory, and Cognition, 13, 531-541.

Light, L. L., Singh, A., \& Capps, J. L. (1986). The dissociation of memory and awareness in young and older adults. Journal of Clinical and Experimental Neuropsychology, 8, 62-74.

Mandler, G. (1980). Recognizing: The judgment of previous occurrence. Psychological Review, 87, 252-271.

Mark, R. E., Rugg, M. D., Roberts, R. C., \& Gilchrist, J. (1995). Effects of age on event-related potentials evoked by word repetition in direct and indirect memory tasks. Society for Neuroscience Abstracts, 21, 1709.

Marsolek, C. J., Kosslyn, S. M., \& Squire, L. R. (1992). Formspecific visual priming in the right cerebral hemisphere. Journal of Experimental Psychology: Learning, Memory, and Cognition, 18, 492-508.

McCarthy, G., \& Wood, C. C. (1985). Scalp distributions of event-related potentials: An ambiguity associated with analysis of variance models. Electroencephalography and Clinical Neurophysiology, 62, 203-208.

Milner, B. (1965). Memory disturbance after bilateral hippocampal lesions. In P. M. Milner \& S. Glickman (Eds.), Cognitive processes and the brain. Princeton, NJ: Van Nostrand.

Mitchell, D. B. (1989). How many memory systems? Evidence from aging. Journal of Experimental Psychology: Learning, Memory, and Cognition, 15, 31-49.

Morton, J. (1969). Interaction of information in word recognition. Psychological Review, 76, 165-178.

Moscovitch, M. (1982a). Multiple dissociations of function in amnesia. In L. S. Cermak (Ed.), Human memory and amnesia (pp. 337-370). Hillsdale, NJ: Erlbaum.

Moscovitch, M. (1982b). A neuropsychological approach to perception and memory in normal and pathological aging. In F. I. M. Craik \& S. Trehub (Eds.), Aging and cognitive processes (pp. 55-78). New York: Plenum Press.

Musen, G., \& Treisman, A. (1990). Implicit and explicit memory for visual patterns. Journal of Experimental Psychology: Learning, Memory, and Cognition, 16, 127-137.

Nagy, M. E., \& Rugg, M. D. (1989). Modulation of event-related potentials by word repetition: The effects of inter-item lag. Psychophysiology, 26, 431-436.

Neville, H., Kutas, M., Chesney, G., \& Schmidt, A. (1986). Event-related brain potentials during initial encoding and recognition memory of congruous and incongruous words. Journal of Memory and Language, 25, 75-92.

Nielsen-Bohlman, L., \& Knight, R. T. (1995). Prefrontal alterations during memory processing in aging. Cerebral Cortex, 5, 541549.

Paller, K. A., \& Kutas, M. (1992). Brain potentials during memory retrieval provide neurophysiological support for the distinction between conscious recollection and priming. Journal of Cognitive Neuroscience, 4, 375-391.

Paller, K. A., Kutas, M., \& McIsaac, H. K. (1995). Monitoring conscious recollection via the electrical activity of the brain. Psychological Science, 6, 107-111.

Paul, D. D., \& Sutton, S. (1972). Evoked potential correlates of response criterion in auditory signal detection. Science, 177, $362-364$

Pfefferbaum, A., Ford, J. M., Wenegrat, B. G., Roth, W. T., \& Kopell, B. S. (1984). Clinical application of the P3 component of event-related potentials: I. Normal aging. Electroencephalography and Clinical Neumophysiology, 59, 85-103.

Polster, M. R., Nadel, L., \& Schacter, D. L. (1991). Cognitive neuroscience analysis of memory: A historical perspective. Joumal of Cognitive Neuroscience, 3, 95-116.

Poon, L. W., \& Fozard, J. L. (1980). Age and word frequency effects in continuous recognition memory. Journal of Gerontology, 35, 77-86.

Reuckl, J. G. (1990). Similarity effects in word and pseudoword repetition priming. Journal of Experimental Psychology: Learning, Memory, and Cognition, 16, 374-391.

Rugg, M. D. (1990). Event-related brain potentials dissociate repetition effects of high- and low-frequency words. Memory \& Cognition, 18, 367-379.

Rugg, M. D. (1995). Event-related potential studies of human memory. In M. S. Gazzaniga (Ed.), The cognitive neurosciences (pp. 789-801). Cambridge, MA: MIT Press.

Rugg, M. D., Brovendani, P., \& Doyle, M. C. (1992). Modulation of event-related potentials (ERPs) by word repetition in a task with inconsistent mapping between repetition and response. Electroencephalography and Clinical Neurophysiology, 84, 521531.

Rugg, M. D., \& Doyle, M. C. (1992). Event-related potentials and recognition memory for low- and high-frequency words. Journal of Cognitive Neuroscience, 4, 69-79.

Rugg, M. D., Doyle, M. C., \& Wells, T. (1995). Word and nonword repetition within- and across-modality: An event-related potential study. Journal of Cognitive Neuroscience, 7, 209-227.

Rugg, M. D., \& Nagy, M. E. (1987). Lexical contribution to nonword-repetition effects: Evidence from event-related potentials. Memory \& Cognition, 15, 473-481.

Rugg, M. D., \& Nagy, M. E. (1989). Event-related potentials and recognition memory for words. Electroencephalography and Clinical Neurophysiology, 72, 395-406.

Rugg, M. D., Pearl, S., Walker, P., Roberts, R. C., \& Holdstock, J. $S$. (1994). Word repetition effects on event-related potentials in healthy young and old subjects, and in patients with Alzheimertype dementia. Neuropsychologia, 32, 381-398.

Scarborough, D. L., Cortese, C., \& Scarborough, H. S. (1977). Frequency and repetition effects in lexical memory. Journal of Experimental Psychology: Human Perception and Performance, 3, 1-17.

Schacter, D. L., Chiu, C.-Y. P., \& Ochsner, K. N. (1993). Implicit memory: A selective review. Annual Review of Neuroscience, $16,159-182$.

Schacter, D. L., Cooper, L. A., \& Delaney, S. M. (1990). Implicit memory for unfamiliar objects depends on access to structural descriptions. Joumal of Experimental Psychology: General, $119,5-24$.

Shimamura, A. P. (1990). Aging and memory disorders: A neuropsychological analysis. In M. L. Howe, M. J. Stones, \& C. J. Brainerd (Eds.), Cognitive and behavioral performance factors in atypical aging (pp. 37-65). New York: Springer-Verlag.

Smith, M. E. (1993). Neurophysiological manifestations of recollective experience during recognition memory judgments. Journal of Cognitive Neuroscience, 5, 1-13.

Smith, M. E., \& Guster, K. (1993). Decomposition of recognition memory event-related potentials yields target, repetition, and retrieval effects. Electroencephalography and Clinical Neurophysiology, 86, 335-343.

Smith, M. E., \& Haigren, E. (1987). Event-related potentials during lexical decision: Effects of repetition, word frequency, pronounceability, and concreteness. In R. Johnson, Jr., J. W. Rohrbaugh, \& R. Parasuraman (Eds.), Current trends in event-related potential research (pp. 417-421). Amsterdam: Elsevier. 
Smith, M. E., \& Oscar-Berman, M. (1990). Repetition priming of words and pseudowords in divided attention and in amnesia. Journal of Experimental Psychology: Learning, Memory, and Cognition, 16, 1033-1042.

Squire, L. R. (1992). Declarative and nondeclarative memory: Multiple brain systems supporting learning and memory. Journal of Cognitive Neuroscience, 4, 232-243.

Squire, L. R., Knowlton, B., \& Musen, G. (1993). The structure and organization of memory. Annual Review of Psychology, 44, 453-495.

Squire, L. R., Ojemann, J. G., Miezin, F. M., Petersen, S. E., Videen, T. O., \& Raichle, M. E. (1992). Activation of the hippocampus in normal humans: A functional anatomical study of memory. Proceedings of the National Academy of Science, 89, 1837-1841.

Squires, K. C., Hillyard, S. A., \& Lindsay, P. H. (1973). Vertex potentials evoked during auditory signal detection: Relation to decision criteria. Perception \& Psychophysics, 14, 265-272.

Squires, N. K., Squires, K. C., \& Hillyard, S. A. (1975). Two varieties of long-latency positive waves evoked by unpredictable auditory stimuli in man. Electroencephalography and Clinical Neurophysiology, 38, 387-401.

Swick, D., \& Knight, R. T. (1995). Contributions of right inferior temporal-occipital cortex to visual word and nonword priming. NeuroReport, 7, 11-16.

Swick, D., Kutas, M., \& Neville, H. (1994). Localizing the neural generators of event-related brain potentials. In A. Kertesz (Ed.), Localization and neuroimaging in neuropsychology (pp. 73121). San Diego, CA: Academic Press.

Tulving, E. (1983). Elements of episodic memory. Oxford, England: Clarendon Press.

Tulving, E., Hayman, C. A. G., \& Macdonald, C. A. (1991). Long-lasting perceptual priming and semantic learning in amnesia: A case experiment. Journal of Experimental Psychology: Learning, Memory, and Cognition, 17, 595-617.

Tulving, E., \& Schacter, D. L. (1990). Priming and human memory systems. Science, 247, 301-306.

Tulving, E., Schacter, D. L., \& Stark, H. A. (1982). Priming effects in word fragment completion are independent of recognition memory. Journal of Experimental Psychology: Learning, Memory, and Cognition, 8, 336-342.

Van Petten, C., Kutas, M., Kluender, R., Mitchiner, M., \& Mclsaac, H. (1991). Fractionating the word repetition effect with event-related potentials. Joumal of Cognitive Neuroscience, 3, 131-150.

Warrington, E. K., \& Weiskrantz, L. (1970). Amnesic syndrome: Consolidation or retrieval? Nature, 228, 628-630.

\section{Appendix}

\section{Further Tests of ERP Repetition Effects}

The first set of analyses isolated the source of the ERP repetition effects by comparing stimuli repeated at each lag to first presentations. Because the Repetition $\times$ Age interaction was significant in most intervals, analyses for the young and old groups were performed separately. Priming was evaluated with planned comparisons between new items and repeated items at the $\mathrm{Pz}$ electrode, where the effects were greatest. Because a significant Stimulus Type $\times$ Repetition interaction was rarely obtained, values were collapsed across stimulus type. Additional contrasts determined whether the length of the delay between first and second presentation influenced the ERP response.

\section{Experiment 1}

For young adults, lag 0 stimuli evoked greater positivity than new items from $300-500 \mathrm{~ms}$ (Table A1). By $500 \mathrm{~ms}$ (and persisting for the duration of the epoch), responses to lag 0 stimuli were significantly less positive than to new stimuli. Lag 1-3 stimuli elicited greater positivity from 300-500 ms. Comparisons between lag 9-19 and new items did not reach significance. By contrast, repetition effects in the elderly were larger and of longer duration. Lag 0 stimuli were significantly more positive from $400-600 \mathrm{~ms}$. Responses to lag 1-3 stimuli were significantly larger from

Table A1

Results From Contrasts Between New and Repeated Stimuli (at Each of the Three Lags) for the Lexical Decision Task

\begin{tabular}{|c|c|c|c|c|c|c|c|c|c|c|}
\hline \multirow[b]{2}{*}{ Condition } & \multicolumn{2}{|c|}{$300-400$} & \multicolumn{2}{|c|}{$400-500$} & \multicolumn{2}{|c|}{$500-600$} & \multicolumn{2}{|c|}{$600-700$} & \multicolumn{2}{|c|}{$700-800$} \\
\hline & $F$ & $M S E$ & $F$ & $M S E$ & $F$ & MSE & $F$ & $M S E$ & $F$ & $M S E$ \\
\hline \multicolumn{11}{|l|}{ Young } \\
\hline Lag 0 & $36.64^{* * *}$ & 212 & $15.76^{* *}$ & 116 & $11.06 * *$ & 73 & $44.45 * * *$ & 288 & $45.51^{* * *}$ & 273 \\
\hline Lag 1-3 & $4.83^{*}$ & 28 & 7.6 & 57 & 2.97 & 19 & 2.89 & 19 & $18.05^{* *}$ & 108 \\
\hline Lag 9-19 & 2.02 & 12 & 1.99 & 15 & 1.19 & 8 & 1.70 & 11 & $11.49 * *$ & 69 \\
\hline \multicolumn{11}{|l|}{ Elderly } \\
\hline Lag 0 & 4.05 & 8 & $66.38 * * *$ & 186 & $19.92^{* *}$ & 80 & 0.26 & 1 & $6.22 *$ & 39 \\
\hline Lag 1-3 & $12.88 * *$ & 25 & $17.94 * *$ & 50 & $25.71 * * *$ & 103 & $19.21 * * *$ & 81 & 0.99 & 6 \\
\hline Lag 9-19 & $4.86^{*}$ & 9 & 4.13 & 63 & $9.01 *$ & 36 & $12.64 * *$ & 53 & 1.17 & 7 \\
\hline
\end{tabular}

Note. Mean amplitude measurements were taken from the midline parietal electrode for five consecutive 100 -ms intervals. The degrees of freedom for all $F$ values are 1,8 .

${ }^{*} p<.05 . \quad * * p<.01 . \quad * * * p<.001$. 
Table A2

Results From Contrasts for the Lexical Decision Task

\begin{tabular}{|c|c|c|c|c|c|c|c|c|c|c|}
\hline \multirow[b]{2}{*}{ Condition } & \multicolumn{2}{|c|}{$300-400$} & \multicolumn{2}{|c|}{$400-500$} & \multicolumn{2}{|c|}{$500-600$} & \multicolumn{2}{|c|}{$600-700$} & \multicolumn{2}{|c|}{$700-800$} \\
\hline & $F$ & $\overline{M S E}$ & $F$ & $\overline{M S E}$ & $F$ & $\overline{M S E}$ & $F$ & $\overline{M S E}$ & $F$ & $\overline{M S E}$ \\
\hline \multicolumn{11}{|l|}{ Young } \\
\hline Lag 0 vs. lag 1-3 & $11.72 * *$ & 559 & 2.25 & 129 & $18.43 * * *$ & 1,043 & $20.29 * *$ & 1,094 & $6.77^{*}$ & 352 \\
\hline Lag 0 vs. lag 9-19 & $15.78^{* *}$ & 752 & $7.80^{*}$ & 448 & $12.39 * *$ & 702 & $24.08 * * *$ & 1,298 & $12.66 * *$ & 657 \\
\hline Lag $1-3$ vs. lag 9-19 & 0.30 & 14 & 1.67 & 96 & 0.60 & 34 & 0.16 & 9 & 0.91 & 47 \\
\hline \multicolumn{11}{|l|}{ Elderly } \\
\hline Lag 0 vs. lag 1-3 & 1.25 & 14 & $23.62 * * *$ & 304 & 0.90 & 28 & $20.96 * * *$ & 709 & $9.47 *$ & 408 \\
\hline Lag 0 vs. lag 9-19 & 0.003 & 0 & $49.97 * * *$ & 643 & 0.70 & 22 & $13.47 * *$ & 456 & 0.01 & 0 \\
\hline Lag 1-3 vs. lag 9-19 & 1.37 & 15 & $4.88^{*}$ & 63 & 3.18 & 99 & 0.82 & 28 & 0.01 & 1 \\
\hline
\end{tabular}

Note. These comparisons were between repeated stimuli at each of the three lags (collapsed across central, parietal, temporal, and occipital electrodes). The degrees of freedom for all $F$ values are 1,8 .

${ }^{*} p<.05$. ${ }^{* *} p<.01 . \quad * * * p<.001$.

$300-700 \mathrm{~ms}$. The LPC to lag 9-19 items was greater from $300-400$, showed a trend at $400-500(p<.08)$, and was again larger from 500-700 ms.

Parallel to their intact RT priming for words in the lexical decision task, the elderly showed marked ERP word repetition effects at all delays. However, words and nonwords did not differ in the pattern of ERP changes elicited by stimulus repetition, implying a dissociation between behavioral and electrophysiological measures of nonword priming in the elderly. Specifically, older participants showed significantly less behavioral facilitation for repeated nonwords than for repeated words. Thus, the ERPs may index processes that are not reflected in behavioral measures of nonword priming.

The length of delay between first and second presentation influenced the size of the ERP response in both groups, with immediately repeated stimuli eliciting greater positivity between 300 and 500 ms than items repeated at longer delays. For young adults, ERPs to lag 0 stimuli were more positive going from $300-400$ and less positive from $500-800 \mathrm{~ms}$ than ERPs to lag 1-3 items (see Table A2 and Table 3). Similarly, lag 0 stimuli elicited a larger LPC from $300-500$ but were less positive going from 500-800 than lag 9-19 stimuli. There were no differences between lag 1-3 and lag 9-19 items in any time window. For the elderly, the
LPC to immediate repetitions was greater than that to longer lag stimuli at $400-500 \mathrm{~ms}$, whereas the long-delay items were associated with greater positivity than lag 0 items from $600-800 \mathrm{~ms}$. Lag 1-3 stimuli elicited a more-positive response than lag 9-19 stimuli from $400-500 \mathrm{~ms}$, hinting at an age-related decline in the strength of the repetition effect at long delays.

Karayanidis et al. (1991) found a comparable difference between words repeated at lag 0 and at lag 4 , both when overt wordnonword responses were made and when these decisions were made covertly. One interpretation of this phenomenon is that immediate repetitions required little access to semantic memory. At longer delays, it might further be infered that the lexical-semantic processing needed to make a decision was greater. Some researchers did not report a difference between the ERP response to words repeated at short and long delays during lexical decision (Bentin \& Peled, 1990; Nagy \& Rugg, 1989). However, variations in task requirements and methodology make these other studies difficult to compare to the present one.

\section{Experiment 2}

The planned comparisons from young participants (Table A3) revealed that lag 0 stimuli evoked greater positivity than new

Table A3

Results From Contrasts Between New and Repeated Stimuli (at Each of the Three Lags) for the Recognition Memory Task

\begin{tabular}{|c|c|c|c|c|c|c|c|c|c|c|c|c|}
\hline \multirow[b]{2}{*}{ Condition } & \multicolumn{2}{|c|}{$200-300$} & \multicolumn{2}{|c|}{$300-400$} & \multicolumn{2}{|c|}{$400-500$} & \multicolumn{2}{|c|}{$500-600$} & \multicolumn{2}{|c|}{$600-700$} & \multicolumn{2}{|c|}{$700-800$} \\
\hline & $F$ & $M S E$ & $F$ & $M S E$ & $F$ & $M S E$ & $F$ & $M S E$ & $F$ & $M S E$ & $F$ & $M S E$ \\
\hline \multicolumn{13}{|l|}{ Young } \\
\hline Lag 0 & $8.79^{*}$ & 20 & $77.82^{* * * *}$ & 388 & $89.55 * * *$ & 543 & $20.35 * *$ & 158 & 1.40 & 8 & $25.71^{* * *}$ & 166 \\
\hline Lag 1-3 & 4.38 & 10 & $10.57^{*}$ & 53 & $29.04 * * *$ & 176 & $14.69 * *$ & 114 & 0.92 & 5 & 0.11 & 1 \\
\hline Lag 9-19 & $12.72^{*}$ & 29 & $12.79^{*}$ & 64 & $15.07 * *$ & 91 & $11.42 * *$ & 89 & 3.45 & 20 & 2.58 & 17 \\
\hline \multicolumn{13}{|l|}{ Elderly } \\
\hline Lag 0 & $6.02 *$ & 16 & 0.18 & 1 & $17.24 * *$ & 105 & $7.45^{*}$ & 68 & 1.05 & 10 & 0.19 & 2 \\
\hline Lag 1-3 & 0.11 & 0 & 0.60 & 3 & 3.18 & 19 & 4.37 & 40 & 0.41 & 4 & 0.99 & 6 \\
\hline Lag 9-19 & 0.29 & 1 & 0.04 & 0 & 0.51 & 3 & 0.25 & 2 & 1.82 & 17 & 2.96 & 32 \\
\hline
\end{tabular}

Note. Mean amplitude measurements were taken from the midline parietal electrode for six consecutive 100 -ms intervals. The degrees of freedom for all $F$ values are 1,8 .

${ }^{*} p<.05 . \quad{ }^{* *} p<.01 . \quad * * * p<.001$ 
Table A4

Results From Contrasts for the Recognition Memory Task

\begin{tabular}{|c|c|c|c|c|c|c|c|c|c|c|}
\hline \multirow[b]{2}{*}{ Condition } & \multicolumn{2}{|c|}{$300-400$} & \multicolumn{2}{|c|}{$400-500$} & \multicolumn{2}{|c|}{$500-600$} & \multicolumn{2}{|c|}{$600-700$} & \multicolumn{2}{|c|}{$700-800$} \\
\hline & $F$ & $\overline{M S E}$ & $F$ & $\overline{M S E}$ & $F$ & $\overline{M S E}$ & $F$ & $\overline{M S E}$ & $F$ & $\overline{M S E}$ \\
\hline \multicolumn{11}{|l|}{ Young } \\
\hline Lag 0 vs. lag 1-3 & $26.19 * *$ & 1,166 & $21.53^{* * *}$ & 1,042 & 0.39 & 22 & $5.88^{*}$ & 201 & $17.40^{*}$ & 930 \\
\hline Lag 0 vs. lag 9-19 & $21.80 * *$ & 971 & $36.59 * * *$ & 1,772 & 1.69 & 95 & $12.85 * *$ & 440 & $36.67^{* * *}$ & 1,960 \\
\hline Lag $1-3$ vs. lag 9-19 & 0.20 & 10 & 1.99 & 96 & 0.46 & 26 & 1.35 & 46 & 3.55 & 190 \\
\hline \multicolumn{11}{|l|}{ Elderly } \\
\hline Lag 0 vs. lag 1-3 & 0.06 & 2 & $7.00^{*}$ & 299 & 1.07 & 70 & 0.32 & 19 & 0.56 & 54 \\
\hline Lag 0 vs. lag 9-19 & 0.40 & 13 & $24.29 * *$ & 1,038 & $12.46^{* *}$ & 816 & $5.99 *$ & 351 & $5.59 *$ & 544 \\
\hline Lag $1-3$ vs. lag 9-19 & 0.78 & 26 & 5.21 & 223 & $6.22 *$ & 407 & 3.55 & 208 & 2.62 & 254 \\
\hline
\end{tabular}

Note. Mean amplitude measurements were collapsed across central, parietal, temporal, and occipital electrodes. The degrees of freedom for all $F$ values are 1,8 .

${ }^{*} p<.05 . \quad * * p<.01 . \quad * * * p<.001$.

stimuli from 200 to $600 \mathrm{~ms}$. A trend for lag 1-3 items to elicit greater positivity at $200-300 \mathrm{~ms}(p<.08)$ became significant from 300 to $600 \mathrm{~ms}$. ERPs to lag 9-19 stimuli were significantly more positive going than new items beginning at $200 \mathrm{~ms}$ and continuing through $600 \mathrm{~ms}$ (with a slight trend at $600-700 \mathrm{~ms}, p<.09$ ). Conversely, repetition effects for the explicit memory task were of shorter duration in the elderly. Immediate repetitions elicited more negative-going potentials from $200-300 \mathrm{~ms}(p<.05)$, whereas the onset of the positive shift began at $400 \mathrm{~ms}$ and ended at $600 \mathrm{~ms}$. Responses to lag 1-3 stimuli were marginally greater than first presentations at $500-600 \mathrm{~ms}(p<.07)$. Lag 9-19 items never elicited a positive shift and, in fact, exhibited a trend to be less positive going from 600 to $800 \mathrm{~ms}$.

The length of the delay between first and second presentation again influenced the size and time course of the response (Table A4). For young adults, immediately repeated stimuli elicited greater positivity than lag 1-3 and lag 9-19 stimuli from 300 to 500 and less positivity from $600-800 \mathrm{~ms}$ (see also Table 6 in text). There were no differences between lag 1-3 and lag 9-19 items in any time window. For older adults, the LPC to immediate repetitions was greater than that to lag $1-3$ at $400-500$ and lag 9-19 from $400-800 \mathrm{~ms}$. Lag 1-3 stimuli elicited a more positive response than lag 9-19 stimuli in the 500-600 range, with trends at $400-500 \mathrm{~ms}(p<.06)$ and $600-700 \mathrm{~ms}(p<.09)$. Hence, immediately repeated stimuli consistently elicited the largest and earliest LPCs in both groups, suggesting that even one to three intervening stimuli can reduce the size of the early effect. In young adults, the strength of the repetition effect did not decay between 6 and $12 \mathrm{~s}$ and 30 and $60 \mathrm{~s}$, similar to other studies of verbal recognition memory (Friedman, 1990; Rugg \& Nagy, 1989). Conversely, long-delay items never evoked a repetition effect in older adults. If LPC amplitude is sensitive to the strength of the memory trace for an encoded item (Bentin et al., 1992), the elderly showed a disproportionate decay in trace strength between 6 and $12 \mathrm{~s}$ and 30 and $60 \mathrm{~s}$.
Received December 6, 1995

Revision received April 12, 1996 Accepted April 22, 1996 